\title{
Der späteiszeitliche Tüttensee-Komplex als Ergebnis der Abschmelzgeschichte am Ostrand des Chiemsee-Gletschers und sein Bezug zum „Chiemgau Impakt“" (Landkreis Traunstein, Oberbayern)
}

\author{
Robert Huber $^{1}$, Robert Darga ${ }^{2}$, and Hans Lauterbach ${ }^{3}$ \\ ${ }^{1}$ MARUM - Center for Marine Environmental Sciences, University of Bremen, Leobener Str. 8, \\ POB 330440, 28359 Bremen, Germany \\ ${ }^{2}$ Naturkunde- und Mammut-Museum Siegsdorf, Auenstr. 2, 83313 Siegsdorf, Germany \\ ${ }^{3}$ Hermannstädter Str. 5, 83301 Traunreut, Germany
}

Correspondence: $\quad$ Robert Huber (rhuber@uni-bremen.de)

Relevant dates: $\quad$ Received: 8 November 2019 - Revised: 9 July 2020 - Accepted: 22 July 2020 Published: 28 August 2020

How to cite:

Huber, R., Darga, R., and Lauterbach, H.: Der späteiszeitliche Tüttensee-Komplex als Ergebnis der Abschmelzgeschichte am Ostrand des Chiemsee-Gletschers und sein Bezug zum „Chiemgau Impakt“ (Landkreis Traunstein, Oberbayern), E\&G Quaternary Sci. J., 69, 93-120, https://doi.org/10.5194/egqsj-69-93-2020, 2020.

Kurzfassung: Anhand von sedimentologischen und geländemorphologischen Untersuchungen wird die Abschmelzgeschichte des südöstlichen Chiemsee-Gletschers beschrieben. Mit dem Trockenfallen der Bad Adelholzen-Erlstätter Rinne im Verlaufe des Spätwürm entwickelt sich aus dem Abschmelzen des Eislappens in der Grabenstätter Bucht eine sich ständig tiefer legende konzentrische Abfolge von zunächst peripheren Entwässerungsrinnen, wobei die ältesten Rinnen dieser Phase bei Chieming, die jüngeren dann entsprechend weiter im Süden, in die zentripetale Richtung umschwenken.

Die Entstehung des Tüttensee-Komplexes ist im Kontext dieser Entwicklung zu sehen. Er ist das Ergebnis der glazifluvialen und glazilakustrinen Sedimentation im Einflussbereich des sukzessiven Eisabbaus in der Grabenstätter Bucht in Kombination mit einer Toteisbildung im Bereich des heutigen Tüttensees. Dafür sprechen die stufenartige Abfolge der beschriebenen peripheren Abflussrinnen mit ihren immer tiefer liegenden Abflussniveaus, die Höhengleichheit von drei dieser Rinnen mit den Tüttensee-Terrassen sowie die für die jeweilige Terrassenentstehung typische glazifluviale bzw. deltaartige Sedimentstruktur und -reife. Dieses Ergebnis stellt ein Korrektiv zur Hypothese des ChiemgauImpakts dar, wonach der Tüttensee ein Impaktkrater sein soll. Da diese nun falsifizierte Annahme vor allem im deutschsprachigen Raum von zahlreichen Medien propagiert wird, ist der folgende Artikel auf Deutsch verfasst, um einer breiten Leserschaft zugänglich zu sein.

Abstract: $\quad$ The deglaciation history of the southeastern Chiemsee Glacier is described by sedimentological and terrain morphological investigations. As the Bad Adelholzen-Erlstätter Rinne dried up during the late Würmian, the melting of the ice lobe located in the Grabenstätt bay resulted in a concentric sequence of ever deepening peripheral drainage channels. The oldest channels of this phase changed into a centripetal direction near Chieming, the younger ones did so further south. 
The development of the Tüttensee Complex has to be seen in the context of this development. It is the result of the glaciofluvial and -lacustrine sedimentation triggered by the gradual deglaciation of the Grabenstätt bay in combination with dead ice formation in the area of today's Lake Tüttensee. This is supported by the stepwise sequence of the described peripheral discharge channels with their increasingly lower discharge levels, the level equivalence of three of these channels of this phase with the Tüttensee Terraces as well as the glaciofluvial or deltaic sediment structure or maturity typical for the respective terrace formation. This result is a corrective to the now falsified Chiemgau impact hypothesis that the Tüttensee is supposed to be an impact crater. Since this assumption is propagated by numerous media, especially in the German-speaking countries, the following article is written in German in order to be accessible to a broad readership.

\section{Einleitung}

Das Landschaftsbild des Chiemgaus, am Rande der nördlichen Alpen, ist deutlich von der quartären Vereisungsgeschichte des Inn-Chiemsee-Gletschers geprägt, der seit mehr als hundert Jahren Thema zahlreicher wissenschaftlicher Untersuchungen ist (Abb. 1). Von dieser langen Erkenntnisgeschichte seien hier nur die Arbeiten von Penck (1882) sowie Penck und Brückner (1909) genannt. Das Gebiet des Inn-Chiemsee-Gletschers erfuhr seine erste umfassende Beschreibung und Kartierung durch Troll (1924), die im Wesentlichen noch bis heute gültig sind. Er gliederte die Endmoränenwälle des Würm in vier Phasen, die als Rückzugshalte angesehen wurden, bevor der Gletscher das Zungenbecken vollständig freigab. Die Endmoränenwälle der Kirchseeoner Phase zeichnen den Gletscherrand des Hochwürm nach, gefolgt von den ebenso durchgehenden Moränenzügen des Ebersberger und Ölkofener Stadiums (Abb. 2). Das Stephanskirchener Stadium ist mit undeutlichen und nicht durchgehenden Wällen nur im Bereich des Inn-Gletschers im Rosenheimer Beckens erhalten (Abb. 2).

In den vergangenen Jahren wurde das Chiemsee-Gebiet Gegenstand mehrerer geographischer und geologischer Untersuchungen bzw. Kartierungen (z.B. Knauer, 1935; Wilhelm, 1958; Ganss, 1977; Henry und Rudolph, 1978; Gareis, 1978; Jerz, 1999), die das Bild der Würm-zeitlichen Vereisungsgeschichte weiter vervollständigen konnten. Allerdings blieben einige Fragen bislang ungeklärt. Insbesondere die Rolle glazifluvialer Prozesse blieb nur unvollständig beantwortet (z.B. Gareis, 1978) Sie sind aber für die Entstehungsgeschichte der Würm-zeitlichen Landschaftsformen bedeutsam (siehe German, 1973, und Schneider, 1995). Heute können Lage und Verlauf von trockenliegenden, Würmzeitlichen Abflussrinnen mit neuen Geländemodellen aus LIDAR Aufnahmen sehr genau bestimmt werden (Abb. 3, 5). Mit Hilfe dieser Geländemodelle wollen wir in der vorliegenden Arbeit daher den Versuch unternehmen, das Verständnis der zeitlichen und räumlichen Verflechtung dieser Rinnen zu verbessern und damit die Würm-zeitliche Abschmelzgeschichte des östlichen Chiemsee-Gletschers etwas genauer $\mathrm{zu}$ formulieren.

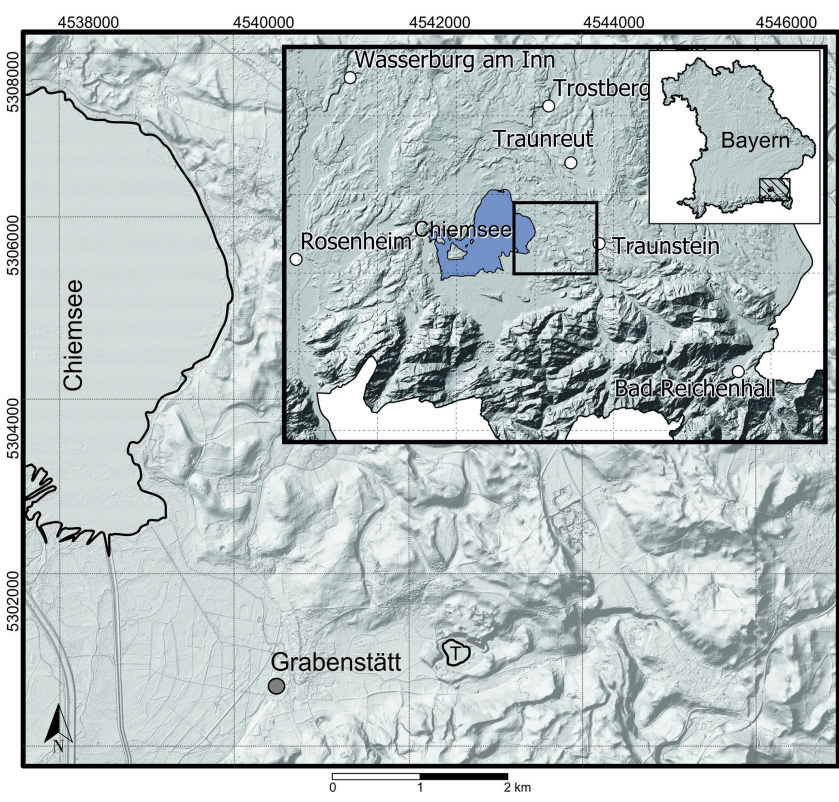

Abb. 1. Lage des Untersuchungsgebietes. $T=$ Tüttensee. Verortung des Arbeitsgebietes siehe Abb. 3. Geobasisdaten (C) Bayerische Vermessungsverwaltung.

Zudem liegt unser Untersuchungsgebiet in dem von Ernstson (2010) postulierten Meteoritenkraterstreufeld zwischen Burghausen und Chiemsee. Innerhalb der jüngsten Würmzeitlichen Moränenwälle und vorgelagerten Entwässerungsrinnen dieses Gebietes liegt der Tüttensee. Dieser See soll nach Vorstellung von Ernstson (2010) auf den Einschlag eines extraterrestrischen Körpers zurückzuführen sein. In der vorliegenden Arbeit überprüfen wir auch diese Impaktthese. Dazu stellen wir die Ergebnisse eigener Begehungen und Kartierungen des Tüttensee-Geländes und dessen weiterer Umgebung vor und werden aus der Zusammenstellung der geomorphologischen und geologischen Beobachtungen sowie sedimentologischer Untersuchungen die Entstehung des späteiszeitlichen Tüttensee-Komplexes im Rahmen der Abschmelzgeschichte am Ostrand des Chiemsee-Gletschers darstellen. 


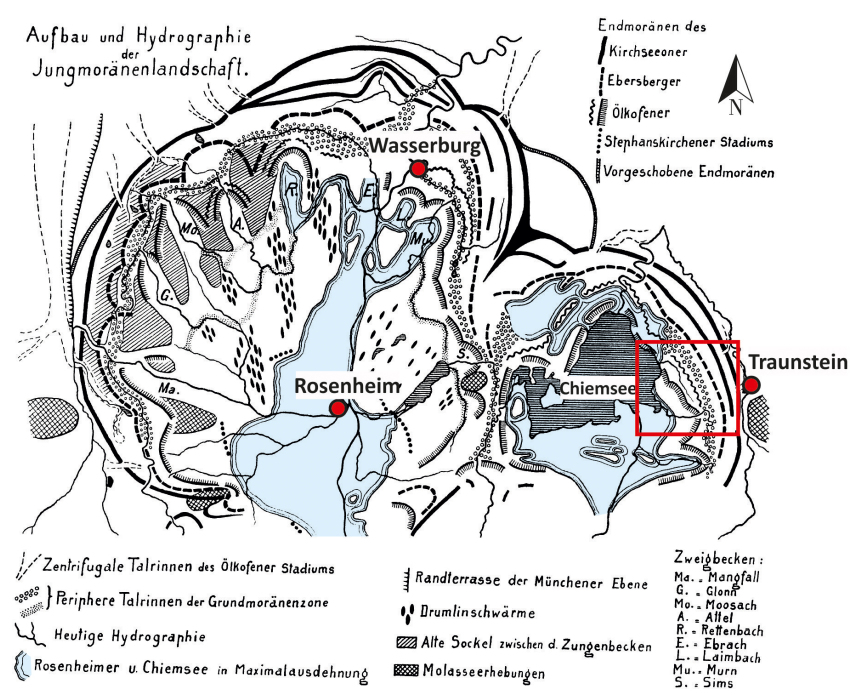

Abb. 2. Lage des Untersuchungsgebietes im Kontext der klassischen Troll'schen Moränenstadien des Inn-Chiemsee Gletschers. Abbildungsgrundlage aus Troll (1924) modifiziert von Darga (2009a).

Das Bayerische Landesamt für Umwelt (2019) hat die Eiszerfallslandschaft des Tüttensees als Geotop mit der Nummer 189R039 ausgewiesen.

\section{Geologischer Rahmen}

Die Grabenstätter Bucht ( $\mathrm{j}$ in Abb. 5) mit dem Tüttensee ist Teil des südöstlichen Chiemsee-Gletschergebietes (Ganss, 1977). In diesem Gebiet herrschen oberflächlich die Ablagerungen und Geländeformen der Würm-Eiszeit vor, die sich hervorragend im Digitalen Geländemodell 1 (DGM1) der Abb. 3 erkennen lassen. Das Gelände ist in erster Linie von Moränenwällen und mehrheitlich ehemaligen Entwässerungstälern geprägt. Der hier von uns als Tüttensee-Komplex vorgestellte Geländeteil wurde bereits von Troll (1924) und Gareis (1978) erfasst, ohne dass jedoch die genaue Abfolge der Abschmelzphasen aufgezeigt wurde.

Der präglaziale Untergrund des Untersuchungsgebietes, der aus dem aufgerichteten Südrand der Vorlandmolasse besteht, ist gelegentlich in der näheren und weiteren Umgebung des Tüttensees in Erosionsgräben aufgeschlossen. Papadeas (1972: Beilage III) stellte mit Hilfe von Bohrdaten das Relief der Oberfläche des voreiszeitlichen Untergrundes im Bereich ungefähr von Chieming bis zur Breite von Bergen dar. Er konnte eine glazigen und fluvial überprägte MolasseOberfläche rekonstruieren, die generell ein leichtes Gefälle in Richtung Norden aufweist und mehrere fluviale Rinnen enthält. Die prägnanteste dieser Rinnen, die etwa $4 \mathrm{~km}$ nordöstlich Bergen beginnt und bis Erlstätt reicht, interpretiert er als Flussbett der Riß-eiszeitlichen Traun. In diesem MolasseRelief fand er auch eine auffallende, in O-W-Richtung verlaufende Rinne. Am östlichen Ende dieser Rinne sitzt in
$26 \mathrm{~m}$ Tiefe ziemlich genau unter dem Tüttensee (Wasserspiegel $526 \mathrm{~m} \mathrm{NN}$ ) eine rundliche Vertiefung mit ungefähr $750 \mathrm{~m}$ Durchmesser (bei Höhenlinie $500 \mathrm{~m}$ NN der MolasseOberfläche). Die Molasse-Höhenlinie von $490 \mathrm{~m}$ NN (also $36 \mathrm{~m}$ unter dem Seespiegel) weist nur noch einen Durchmesser von ca. $550 \mathrm{~m}$ auf. Der Verlauf dieser Rinne nach Westen reicht bis Grabenstätt und biegt hier in südsüdwestliche Richtung um (vgl. Abb. 4, rote Linien).

Veit (1977:212ff.) konnte mit Hilfe von reflexionsseismischen Schussbohrungen im südlichen Chiemsee-Becken (ausschließlich in verlandeten Gebieten) eine Mächtigkeitskarte des jungpleistozänen Seetons erarbeiten, die aufzeigt, dass das Seetonbecken von Übersee in mehrere Teilbecken gegliedert ist. Aus dieser Karte geht hervor, dass im Grabenstätter Moos, also westlich der Grabenstätter Bucht, eine ca. $70 \mathrm{~m}$ tiefe, mit Seeton gefüllte Vertiefung im Untergrund existiert. Sie gehört zu der von Papadeas gefundenen Rinne in der Grabenstätter Bucht. Die Befunde von Papadeas und Veit ergänzen sich also sehr gut (Abb. 4) zur Rekonstruktion des voreiszeitlichen Untergrundes.

\section{Methoden}

Während mehrerer Geländekampagnen in den Jahren 2014 bis 2016 wurde die Umgebung des Tüttensees geologisch kartiert und Aufschlüsse beprobt. In den umgebenden Hügeln und Terrassen des Sees ermöglichten manche Aufschlüsse auch einen Einblick in die innere Struktur. An drei Positionen konnten in Kieskörpern Schichtflächen freigelegt und das Einfallen und die Fallrichtung der Schichten bestimmt werden.

An den Proben wurden Korngrößenanalysen durchgeführt, um Erkenntnisse über das jeweilige Ablagerungsmilieu zu gewinnen. In der Mittel- bis Grobkiesfraktion der Proben wurde an je etwa 100 Körnern der Rundungsgrad gemäß den von Pettijohn et al. (1973) vorgeschlagenen Kategorien bestimmt.

Zur geomorphologischen Analyse wurden über die Bayerische Vermessungsverwaltung des Landesamts für Digitalisierung, Breitband und Vermessung LIDAR-Daten in einer Auflösung bis zu einem Meter bezogen. Um auch die Tiefenmorphologie des Tüttensees in das Geländemodell mit einzubeziehen, wurde die dazu vorliegende $1: 2500$ Tiefenkarte des Bayerischen Landesamtes für Wasserwirtschaft (Grimminger, 1987) digitalisiert, mit Hilfe der Surfer 11 Software in ein kompatibles $1 \mathrm{~m}$ Raster umgewandelt und in das LIDAR Geländemodell integriert. Dadurch konnte eine hochgenaue topographische Karte der näheren Seeumgebung erstellt werden (Abb. 8). Das Softwarepaket wurde auch zur Visualisierung und räumlichen Analyse des Geländes verwendet. Zur Ermittlung von Gefällen und Höhenangaben wurde daneben der BayernAtlas (http://www.geoportal. bayern.de/, letzter Zugriff: 21. März 2018) genutzt. 


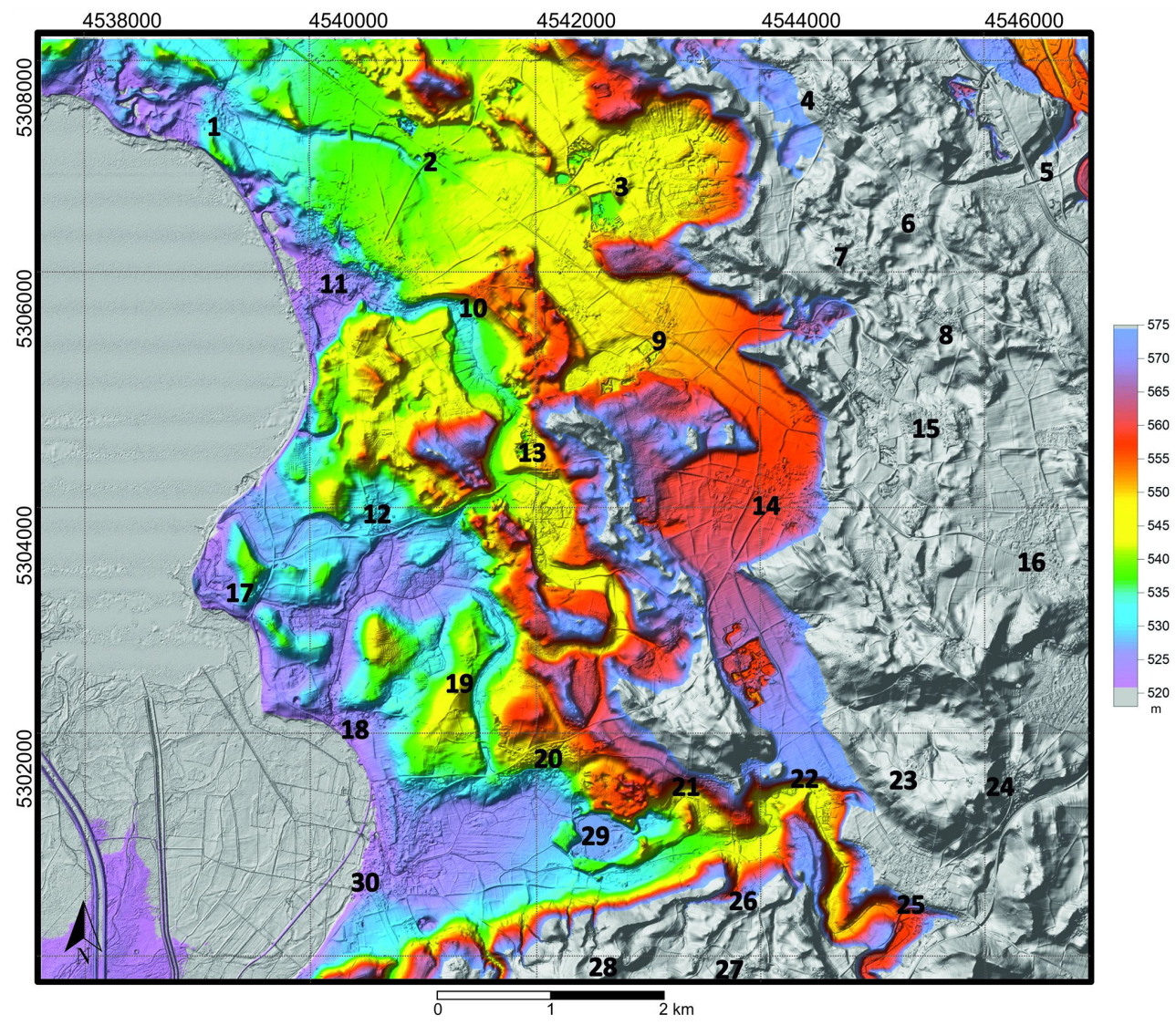

Abb. 3. Digitales Geländemodell, eingefärbt. Norden ist oberer Bildrand. Der Chiemsee ist die graue unstrukturierte Fläche entlang des linken Bildrandes. Höhenlagen am rechten Bildrand in $\mathrm{m}$ NN. Die tiefste Lage (Chiemsee-Niveau) sowie die Höhen höher als $575 \mathrm{~m} \mathrm{NN}$ sind grau dargestellt, und die Farbstufen violett bis hellblau kommen in den tieferen Lagen als auch in den höchsten Lagen vor. Die grau gehaltenen Flächen vor allem im rechten Bildviertel liegen also höher als $575 \mathrm{~m}$ NN. Diese Darstellung zeigt das Gefälle der verschiedenen Rinnen, die in Abb. 5 nur in ihrer zweidimensionalen Ausdehnung dargestellt sind. $1=$ Stöttham, $2=$ Laimgrub, $3=$ Eglsee, $4=$ Nußdorf, $5=$ Weiderting, $6=$ Wang, $7=$ Riederting, $8=$ Höpperding, $9=$ Kraimoos, $10=$ Aufham, $11=$ Chieming, $12=$ Oberhochstätt, $13=$ Innerlohen, $14=$ Erlstätt, $15=$ Wolkersdorf, $16=$ Traunstorf, $17=$ Hagenau , $18=$ Hirschau, 19= Obereggerhausen, 20= Marwang, 21= Hiensdorf, 22= Mühlen, 23 = Tinnerting, 24=Axdorf, 25= Vachendorf, 26=Wipfing, $27=$ Einharting, $28=$ Eckering, $29=$ Tüttensee, $30=$ Grabenstätt. Geobasisdaten $\odot$ Bayerische Vermessungsverwaltung.

Alle Koordinaten sind, wie im genutzten Kartenmaterial, als Gauss-Krüger Koordinaten (Rechts- und Hochwerte) angegeben. Als Quelle für Flurnamen wurde die topografische Karte 1:25000 Blatt 8141 Traunstein (Landesamt für Vermessung und Geoinformation, 2007) verwendet.

\section{Beobachtungen}

\subsection{Geomorphologie}

\subsubsection{Rinnenstrukturen und Trockentäler im südöstlichen Teil des Chiemsee-Gletschers}

Das auffälligste geomorphologische Merkmal im Bereich des ehemaligen Chiemsee-Gletschers sind die markanten, wallförmigen Endmoränenstaffeln, die bereits in den Arbeiten von Troll (1924) und Ganss (1977) beschrieben und klassifiziert wurden. Zwischen den einzelnen Moränenstaffeln befinden sich naturgemäß langgestreckte Täler, die heute als durch ehemalige Wasserläufe geformte Trockentäler vorliegen. Diese Rinnen sind insbesondere im hochauflösenden digitalen Geländemodell in einer neuen Qualität deutlich zu erkennen. Aufgrund von Gefälle und Richtung lassen sich - bezogen auf den Chiemsee - zentrifugal, peripher und zentripetal verlaufende Rinnen unterscheiden (Abb. 5). Zentrifugale Rinnen in unserem Arbeitsgebiet sind die Axdorfer Rinne (1 in Abb. 5) und die Traunstorfer Rinne (a in Abb. 5) zwischen Wang und Weiderting. Sie sind dem Kirchseeoner Stadium (Troll, 1924; Abb. 2) zuzuordnen. Mit dem Eintritt des Eberberger Stadiums (Abb. 2) entwickelte sich die Traunstorfer Rinne zwischen Traunstorf und Wang zu einer peripheren Rinne. Die Wolkersdorfer Rinne (b in Abb. 5) ist als erstes rein peripheres Tal zu erkennen.

Die nun folgenden Rinnen des Ölkofener Stadiums (Abb. 2) hängen alle mit der Entstehung des Tüttensee- 


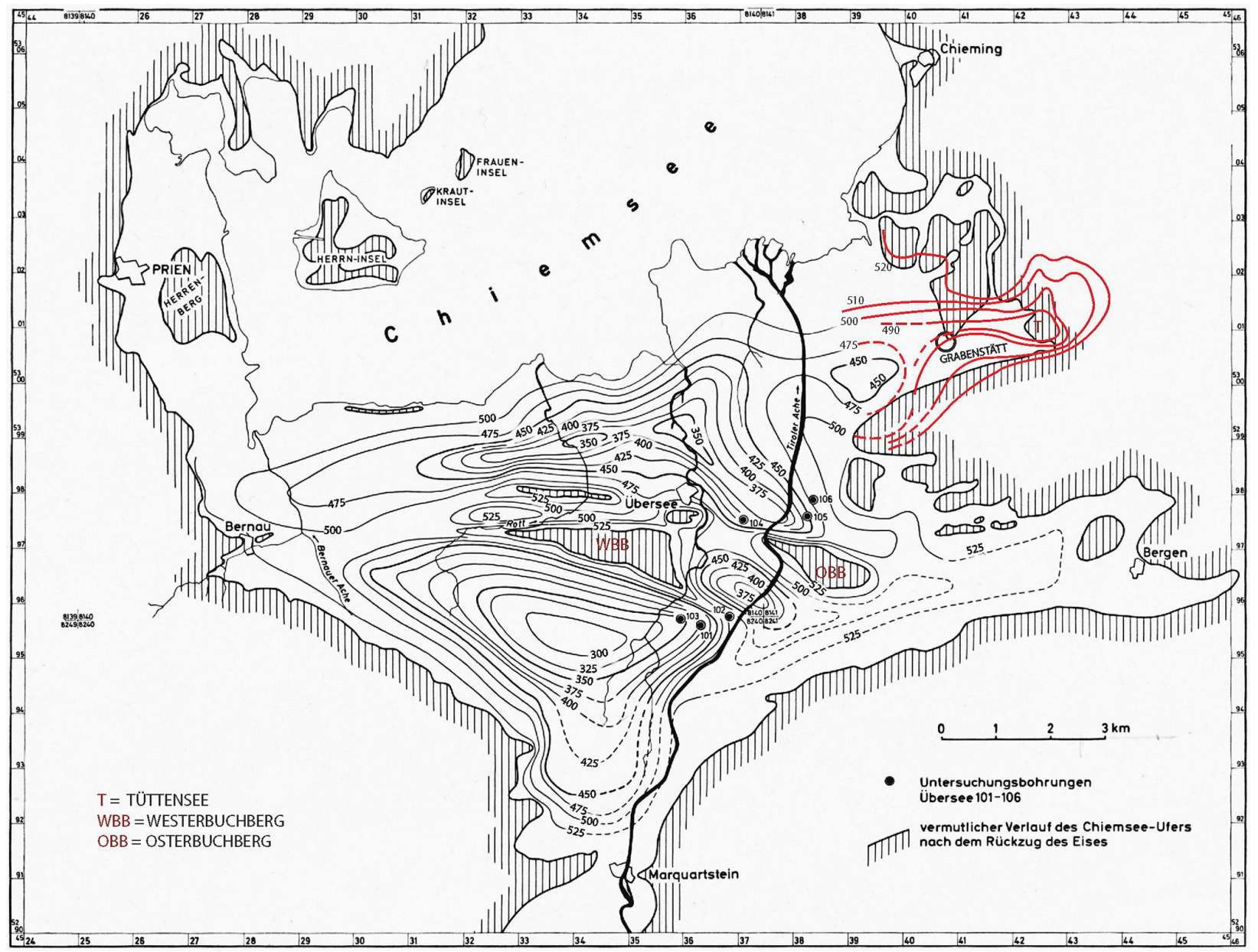

Abb. 4. Darstellung der Untergrundstruktur des verlandeten Chiemsee-Gebietes zwischen Grabenstätt, Bernau und Marquartstein, zusammengestellt und verändert aus den Abbildungen von Veit (1977:213) und Papadeas (1972: Beilage III; Höhenlinien hier zur Unterscheidung von den Höhenlinien von Veit in Rot angegeben). Die Zahlen geben die Höhenlinien in m NN an. Grundinformation zur Ermittlung der ungefähren Schichtmächtigkeit der eiszeitlichen Ablagerungen über dem Molasse-Relief: Der mittlere Wasserspiegel des Chiemsees liegt bei $518 \mathrm{~m} \mathrm{NN}$, die Oberfläche des Grabenstätter Mooses (zwischen Grabenstätt und Tiroler Ache) liegt ca. bei $519 \mathrm{~m}$ NN. Der in der Grafik von Veit eingezeichnete ,vermutliche Verlauf des Chiemsee-Ufers nach dem ,Rückzug des Eises““ ist hypothetisch und zeigt nur einen einzigen Zustand. Die in vorliegender Arbeit gezeigten Abschmelzstadien dagegen geben einen Einblick in die Entwicklung der östlichen Uferlinie des entstehenden Chiemsees anhand der im Gelände feststellbaren Entwässerungsrinnen und der damit verbundenen Eisbarrieren. Der Raum südlich des Chiemsees ist der bereits verlandete Teil des Zungenbeckens. Die subglazial geformten Kolke und Rinnen folgen den ungefähr E-W streichenden Strukturen der Molasse.

Komplexes direkt zusammen. Ihren Verlauf und vor allem ihr Gefälle kann man der Abb. 3 entnehmen. Abbildung 5 zeigt den individuellen Verlauf der einzelnen Rinnen und dadurch z.T. auch deren zeitliche Abfolge.

Die Bad Adelholzen-Erlstätter Rinne (c in Abb. 5) ist im Kartenbild die markanteste periphere Rinne des östlichen Chiemsee-Gebietes. Sie ist bei Erlstätt bis über $900 \mathrm{~m}$ breit und reicht von Bad Adelholzen über Vachendorf und Erlstätt bis Chieming und nördlich Laimgrub. Die Kiesgruben zwischen Vachendorf und Erlstätt schließen innerhalb dieses Trockentales bis in $16 \mathrm{~m}$ Tiefe Kies mit Steinen und Blöcken auf. Dagegen liefern die Kiesgruben rund um Laimgrub deutlich besser sortierten Kies mit weit kleinerer Korngröße. Im
Norden von Laimgrub ist eine Unterscheidung in zwei nacheinander entstandene Entwässerungsrinnen möglich (c1 und c2 in Abb. 5). Der westliche Abflussweg (c2) schwenkt nach Nordwesten um. Es zeichnet sich hier ein Wechsel der Entwässerungsrichtung von peripher zu zentripetal ab. Derzeit sind Kiesgruben bei Eglsee in Abbau und bieten gute Aufschlüsse (Abb. 6).

Sehr auffällig ist die Unterbrechung der Bad AdelholzenErlstätter Rinne zwischen Mühlen und Vachendorf (Abb. 3). Der Grabenstätter Mühlbach hat sich hier tief in diese Rinne gegraben und fließt nun ca. 23 Höhenmeter tiefer in die Grabenstätter Bucht. 


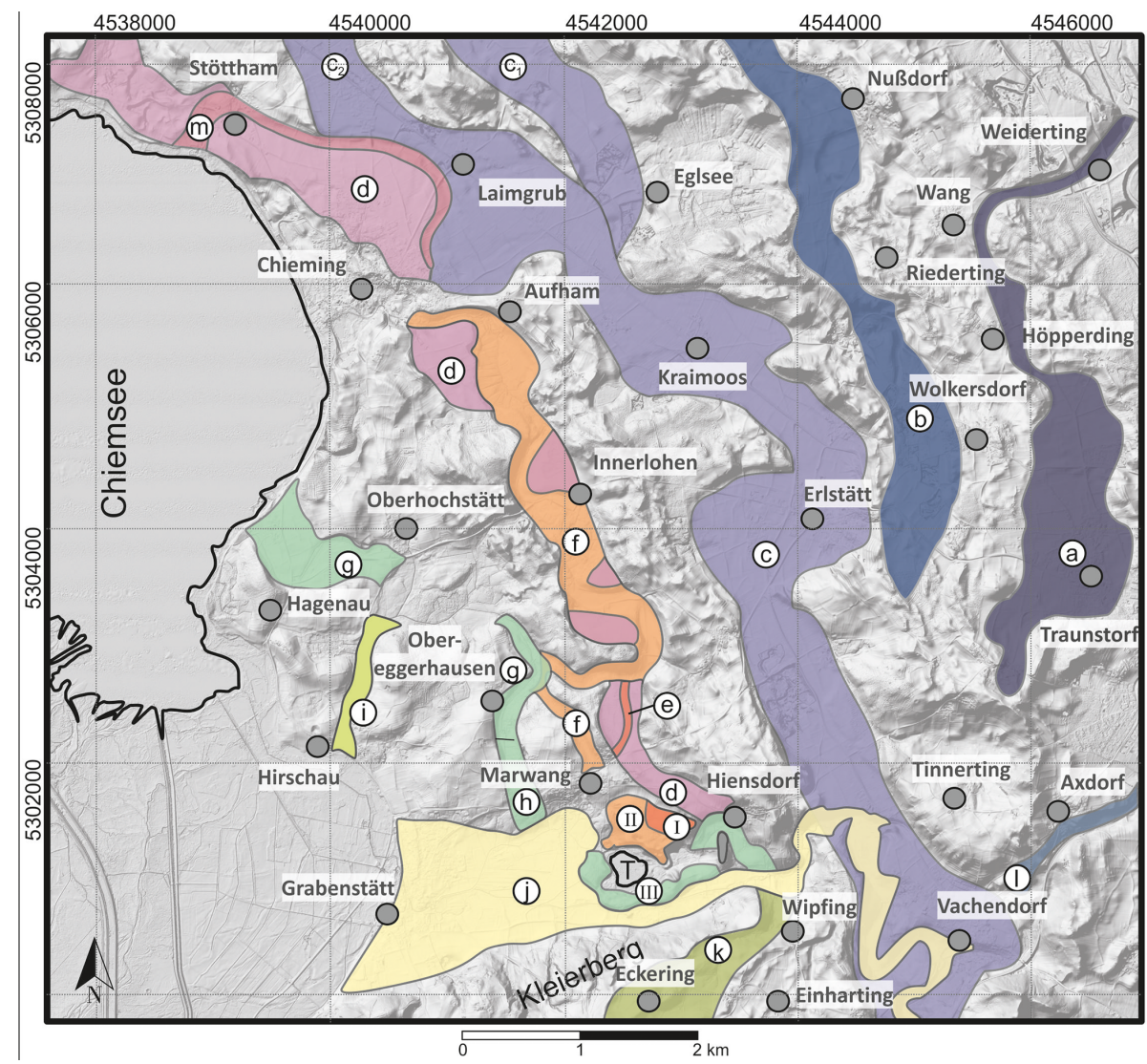

Abb. 5. Übersicht über den Tüttensee-Komplex und die im südöstlichen Chiemsee-Gletscherbereich beobachteten Entwässerungsrinnen. I= Obere Tüttensee-Terrasse I; II = Obere Tüttensee-Terrasse II; III = Untere Tüttensee-Terrasse; T=Tüttensee; a = Traunstorfer Rinne; $b=$ Wolkersdorfer Rinne; $c=$ Bad Adelholzen-Erlstätter Rinne (c1 ältere Terrasse, entwässert Richtung Storfling; $c 2$ jüngere Terrasse, entwässert Richtung Ising); $d=$ Hiensdorfer Rinne; $\mathrm{e}=$ Marwanger Rinne; $\mathrm{f}=$ Kaltenbach-Rinne; $\mathrm{g}=$ Tiefenbach-Rinne; $\mathrm{h}=$ Obereggerhausener Rinne (= der heute nach Süden entwässernde Teil der Tiefenbach-Rinne; der Strich deutet die Wasserscheide an); $\mathrm{i}=$ Hirschauer Rinne; $\mathrm{j}=$ Grabenstätter Bucht; $\mathrm{k}=$ Wipfinger Rinne; $1=$ Axdorfer Rinne; $\mathrm{m}=$ Lohbach-Rinne. Zu beachten ist, dass zu jeder der drei Tüttensee-Terrassen (I, II, III) eine Abflussrinne gehört (vgl. auch Abb. 3). I korrespondiert mit e, II mit f und III mit h und g. Kartengrundlage DGM, Bayerische Vermessungsverwaltung. Geobasisdaten () Bayerische Vermessungsverwaltung.

Die Hiensdorfer Rinne (d in Abb. 5) beginnt bei Hiensdorf als Terrasse, die im Süden an die Grabenstätter Bucht (j in Abb. 5) grenzt (Abb. 12). In einem temporären Aufschluss $(\mathrm{R}=4542685, \mathrm{H}=5301945)$ in diesem Teil der Hiensdorfer Rinne stand Grobkies an. Im DGM ist die schiefe Ebene der Hiensdorfer Rinne bis zum östlichen Ortsende von Marwang zu verfolgen. Unmittelbar östlich von Marwang hat die Hiensdorfer Rinne dann zwei deutliche Uferbegrenzungen und wird ab hier zu einer echten Rinne. Sie verläuft ca. $650 \mathrm{~m}$ in Richtung Norden, um dann nach Osten zu schwenken und in leicht mäandrierender Weise über Kaltenbach, Innerlohen und Aufham in die bei Chieming aufgeschüttete Schwemmebene zu münden. Dieser weitere Verlauf wird durch einzelne Terrassenreste im Tal bei Kaltenbach und Innerlohen sowie durch die korrelierende Höhenlage der Schotter zwischen Aufham und Chieming (Abb. 3) angezeigt. Zwischen Eglsee und Chieming ist die unscheinbare Lohbach-Rinne in die Kiesebene der Hiensdorfer Rinne eingetieft ( $m$ in Abb. 5).
Unmittelbar östlich von Marwang ist in den Boden der Hiensdorfer Rinne eine kleinere Rinne (Marwanger Rinne, e in Abb. 5) eingetieft. Sie hat ihren Anfang bei $R=4542518$, $\mathrm{H}=5302096$, verläuft ca. $300 \mathrm{~m} \mathrm{NNE}$, schwenkt dann nach $\mathrm{N}$ und streicht nach ca. $400 \mathrm{~m}$ in der Art eines Hängetals frei in das dort $7 \mathrm{~m}$ tiefer liegende Tal aus.

Im westlichen Ortsgebiet von Marwang beginnt auf $555 \mathrm{~m}$ $\mathrm{NN}(\mathrm{R}=4542312, \mathrm{H}=5301995)$ die nach NNW weisende Kaltenbach-Rinne (f in Abb. 5). Eine südliche Fortsetzung ist im Gelände nicht vorhanden. Ca. $900 \mathrm{~m}$ weiter nördlich biegt die Kaltenbach-Rinne nach Osten und trifft wieder auf die Hiensdorfer und Marwanger Rinne - allerdings liegt ihre Talsohle um $7 \mathrm{~m}$ tiefer als die der Hiensdorfer und Marwanger Rinne. Deshalb erscheint die Marwanger Rinne an dieser Stelle als Hängetal. Die Kaltenbach-Rinne nimmt von dort an den gleichen Verlauf wie die Hiensdorfer Rinne, schneidet sich jedoch in diese Rinne sehr kräftig ein und reicht bis 


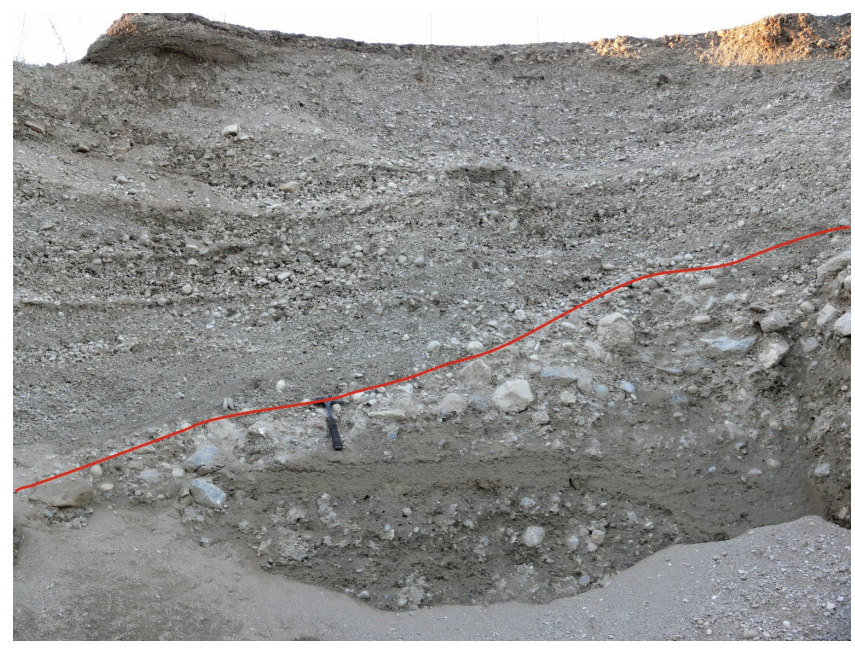

Abb. 6. Schräggeschichtete glazifluviale Kiese über Grundmoräne. Die Linie zeigt den Kontakt an. Die Kiese dieser Grube ( $\mathrm{R}=4542$ 190, H= 5306 942) bei Eglsee gehören zur älteren Entwicklungsstufe der Bad Adelholzen-Erlstätter Trockenrinne (c1 in Abb. 5). Maßstab: Hammer an der Grenzlinie.

nach Chieming. So blieben von der Hiensdorfer Rinne nur wenige Terrassenreste verschont.

Am westlichen Ortsende von Marwang streicht ein deutlich ausgeprägtes, leicht nach Süden hängendes Tal auf ca. $535 \mathrm{~m} \mathrm{NN}$ frei in die Grabenstätter Bucht aus $(\mathrm{R}=4541654$, $\mathrm{H}=5301654)$. In dieser fast gefällelosen Rinne fließt der Eggerhausener Bach. Dieser südliche Talabschnitt ist die Obereggerhausener Rinne (h in Abb. 5). Der Bewuchs auf dem Eggerhausener Talboden weist bereits auf wasserstauenden Untergrund hin. An den Seitenwänden des Eggerhausener Bachs kann man auch ohne große Aufschlussarbeiten hellgrauen Ton erkennen (Abb. 7).

Östlich von Obereggerhausen liegt auf $534 \mathrm{~m} \mathrm{NN}$ eine Wasserscheide $(\mathrm{R}=4541554, \mathrm{H}=5302339)$. Der von hier aus nach Norden abfließende Bach ist der Tiefenbach. Die von ihm durchflossene Rinne ist somit die Tiefenbach-Rinne ( $g$ in Abb. 5), die nur durch die erwähnte sehr flache Wasserscheide von der Obereggerhausener Rinne getrennt ist. Bei Oberhochstätt und nördlich von Hagenau hat die TiefenbachRinne zwei Prallhänge (,Krümmling“ der topographischen Karte) in die Moränenlandschaft erodiert. Diese Rinne endet bei Unterhochstätt abrupt, frei ins Chiemsee-Becken ausstreichend an einer Terrassenkante $(\mathrm{R}=4539395, \mathrm{H}=$ 5304071 ) auf ca. $526 \mathrm{~m} \mathrm{NN}$, also ca. $8 \mathrm{~m}$ über dem heutigen Chiemsee-Niveau. In den Entwässerungsgräben in der Wiese westlich von Oberhochstätt (beim Krümmling, z.B. auf Höhe $528 \mathrm{~m} \mathrm{NN}, \mathrm{R}=4539970, \mathrm{H}=5303729$ ) werden in ca. $70 \mathrm{~cm}$ Tiefe hellgraue Tone mit akzessorischen, bis über faustgroßen Geröllen angetroffen. Diese Tone ähneln denen von Obereggerhausen (Abb. 7) stark.

Die Hirschauer Rinne (i in Abb. 5) zweigt bei Oberhochstätt (ca. $526 \mathrm{~m} \mathrm{NN}$ ) von der Tiefenbach-Rinne ab. Sie zieht

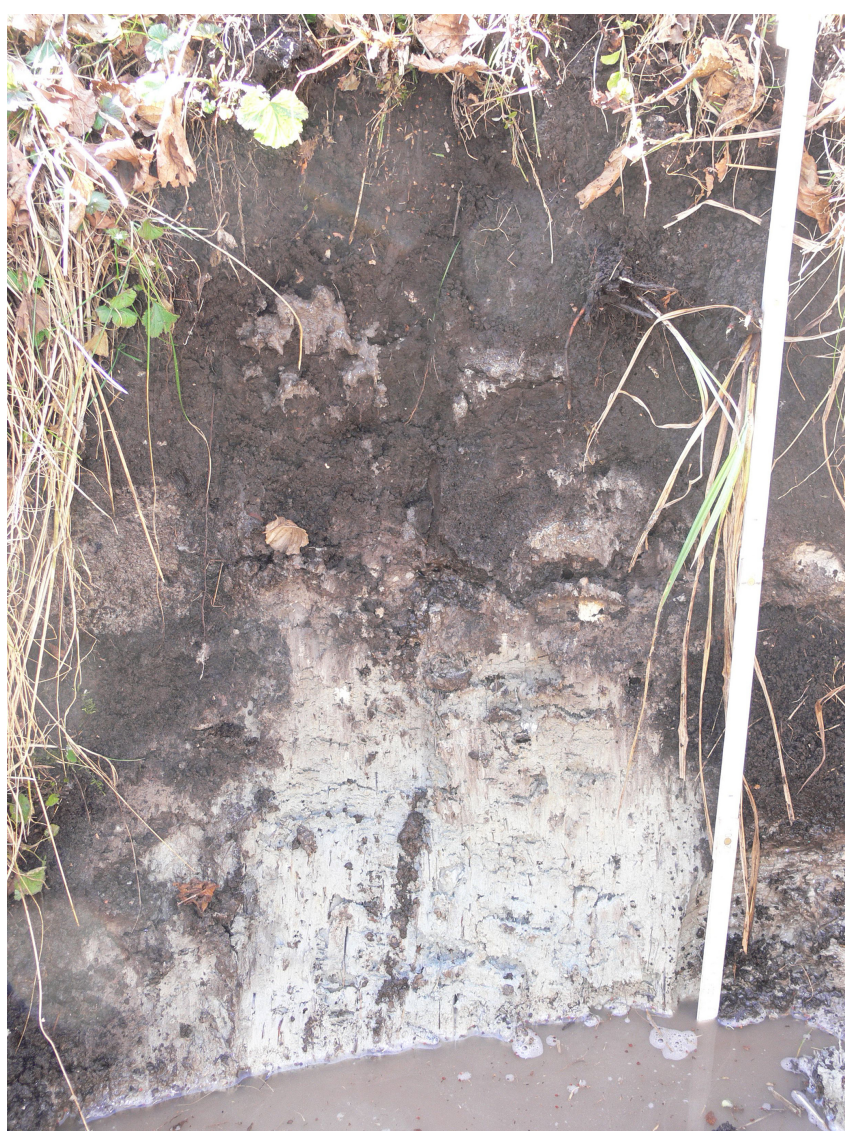

Abb. 7. Ein Schurf am Grabenrand des Obereggerhausener Bachs zeigt unter humusreicher Mudde fast weißen Ton, der nur ganz wenige größere Gerölle enthält. Maßstab rechts.

südwärts nach Hirschau und endet auf etwa $522 \mathrm{~m} \mathrm{NN}$ an einer angedeuteten Geländekante der Grabenstätter Bucht.

Die jüngste Rinne ist die Grabenstätter Bucht (j in Abb. 5), die vom Grabenstätter Mühlbach durchflossen wird. Die geologische Karte (Ganss, 1977) zeigt östlich, entlang der von Grabenstätt nach Hirschau verlaufenden Geländekante spätglaziale bis frühholozäne Kiese. Westlich dieser Kante befindet sich die Verlandungsfläche des Grabenstätter Mooses. Die Geländekante liegt im Süden mehr als $8 \mathrm{~m}$ über dem Grabenstätter Moos und senkt sich nach Norden hin auf weniger als $2 \mathrm{~m}$ Höhe bei Grabenstätt, um Richtung Hirschau wieder leicht anzusteigen. Diese Geländekante begrenzt die Grabenstätter Bucht nach Westen hin.

Die Rinne von Wipfing (k in Abb. 5) wurde der Vollständigkeit halber erst nach Zusammenschau der Ergebnisse mit in die Untersuchung aufgenommen. Es handelt sich um jene Rinne, welche die Nordostseite des Kleierbergs entwässert. Diese Rinne wird in der Diskussion berücksichtigt, obwohl ihr kein direkter Einfluss auf den Tüttensee-Komplex zugeschrieben wird, sondern „nur“ auf die Anfangsphase der hier dargelegten Entwicklung der Rinnenabfolge. 


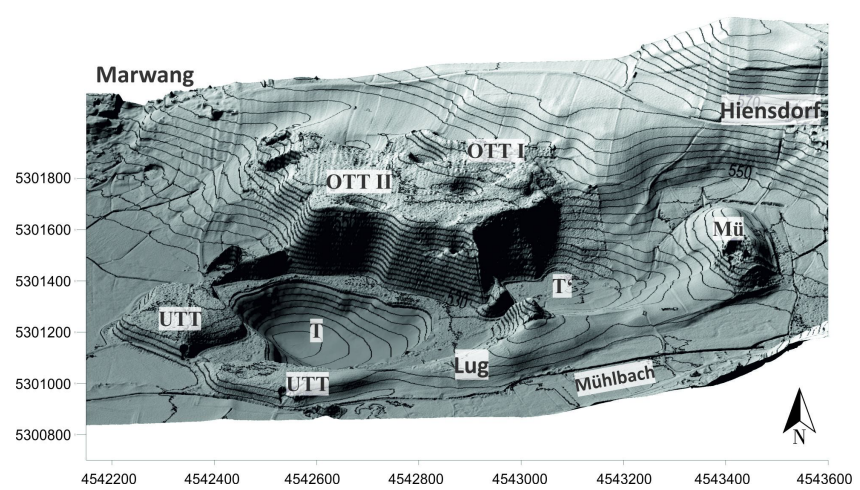

Abb. 8. Digitales Geländemodell des Tüttensee-Komplexes. Blick ungefähr nach Norden. Ost-West-Erstreckung ca. 1,8 km. Abstand der Höhenlinien ist $2 \mathrm{~m}$. T = Tüttensee; $\mathrm{T}^{\prime}=$ östlich des Tüttensees gelegene Senke; Mü=der Hügel $300 \mathrm{~m}$ nordwestlich von Mühlbach; OTT I= die ältere, OTT II=die jüngere der beiden Oberen Tüttensee-Terrassen; UTT = die Untere Tüttensee-Terrasse; Lug $=$ der Weiler Lug. Geobasisdaten (C) Bayerische Vermessungsverwaltung.

\subsubsection{Die Gliederung der Umgebung des Tüttensees: Der Tüttensee-Komplex}

Im östlichen Teil der heute trocken liegenden Grabenstätter Bucht liegt der Tüttensee, der von terrassenartigen Erhebungen umgeben ist, die sich in ihrer Form deutlich von der Umgebung abgrenzen. Diese Geländestrukturen werden wir daher im Weiteren als Tüttensee-Komplex bezeichnen.

Fünf geomorphologische Haupteinheiten (Abb. 8) können innerhalb des Tüttensee-Komplexes abgegrenzt werden: (1) Eine auffällige, hochgelegene, in zwei Ebenen angelegte große Terrasse im nördlichen Bereich des Tüttensees. (2) Eine wallartige, tiefer gelegene Terrasse am westlichen und südlichen Ende des Sees. (3) Der Rücken von Lug, ein langgezogener, von Richtung Südwest-Nordost nach Süd-Nord umbiegender Geländerücken, der südlich des Tüttensees in die unter (2) genannte südliche Terrasse übergeht. (4) Der zwischen Mühlbach und Hiensdorf liegende Hügel, der aufgrund seiner Sedimentstrukturen zum Tüttensee-Komplex gehört. (5) Inmitten dieser Terrassen und Rücken liegt die Senke des Tüttensees selbst und unmittelbar östlich anschließend eine kleinere, bereits verlandete Senke.

\section{Die Oberen Tüttensee-Terrassen (OTT I und OTT II)}

Diese auffällige, im Gegensatz zur Umgebung weitgehend ebene, großflächige Geländeform schließt an das nördliche Ufer des Tüttensees an. Die in zwei Stufen geteilte Terrasse besteht aus einem annähernd oval geformten Körper mit einer Längsachse in Richtung Westnordwest, dessen scharf abgegrenzte südliche Flanken steil Richtung See hin abfallen. Diese Terrasse wirkt wie ein Fremdkörper auf der sanft hügeligen E-W verlaufenden Hügelkette zwischen den Dörfern Hiensdorf und Marwang. Eine Reihe von unregelmäßig

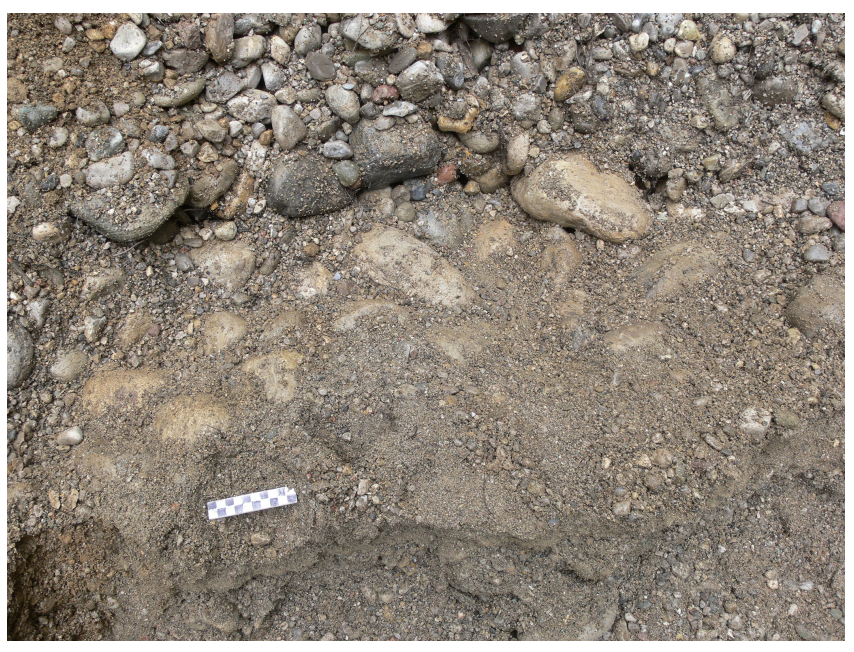

Abb. 9. Freigelegtes Profil im „Kies“ des Probenpunktes TS4 am Westrand der Oberen Tüttensee-Terrasse II. Von unten nach oben: sandiger Feinkies, Sand, Steinlage, matrixfreier Kies.

angeordneten, kleineren Kiesgruben markiert die nördliche Grenze der Terrasse. Die oberste und damit älteste, durch mehrere kleinere Senken gekennzeichnete Fläche mit einer mittleren Höhe von etwa $560 \mathrm{~m}$ NN bildet den nordöstlichen Teil. Sie ist durch eine umlaufende Terrassenkante abgegrenzt und soll im Folgenden als Obere Tüttensee-Terrasse I (OTT I) genannt werden. Die mittlere Höhe der OTT I korrespondiert mit der Höhe des Beginns der Marwanger Rinne (e in Abb. 5; vgl. Tabelle 1).

Der zweite, größere Terrassenbereich ist ein ebenfalls fast horizontales Plateau mit einer mittleren Höhe von etwa $556 \mathrm{~m} \mathrm{NN}$, das zwei deutliche, im Grundriss ovale Gruben enthält. Die Nordwest-Südost verlaufende Längsachse dieser, als Obere Tüttensee-Terrasse II (OTT II) benannten Fläche, ist parallel zu der im Nordosten benachbarten Hiensdorfer Rinne. Ihre Flanken fallen steil nach Westen, Süden und Osten ab. Hervorzuheben ist hier, dass besonders im westlichen Teil beider Terrassen Profile mit deutlicher Schrägschichtung und matrixfreien Grobkiesen aufgeschlossen sind (Abb. 9). Am Osthang treten im basalen Bereich dagegen Diamikte auf. Die mittlere Höhe der OTT II korrespondiert mit dem Beginn der Kaltenbach-Rinne (vgl. Tabelle 1).

\section{Die Untere Tüttensee-Terrasse (UTT)}

Die Höhe der unteren Terrasse reicht von $537 \mathrm{~m}$ NN im Süden bis zu $533 \mathrm{~m} \mathrm{NN}$ im Norden, ist also deutlich niedriger als die beiden zuvor beschriebenen oberen Terrassen. Sie besteht aus zwei Teilen: Eine im Umriss annähernd rhombenförmige Terrasse im Westen des Tüttensees, sowie einer langgestreckten, E-W gerichteten Terrasse im Süden des Sees.

Während die Oberfläche des westlichen Teiles durchgehend horizontal abgeflacht erscheint, hat der längliche Ter- 
Tabelle 1. Die drei Tüttensee-Terrassen und ihre dazugehörigen Abflüsse.

\begin{tabular}{llll}
\hline & Terrassenhöhe & Entwässerung & Überlaufhöhe \\
\hline $\begin{array}{l}\text { Obere Tüttensee-Terrasse 1 } \\
\text { (I in Abb. 5) }\end{array}$ & ca. 560 m NN & $\begin{array}{l}\text { über Marwanger Rinne (e in Abb. 5) Überlauf } \\
\text { heutiges Gelände östlicher Ortsrand Marwang }\end{array}$ & ca. 560 m NN \\
\hline $\begin{array}{l}\text { Obere Tüttensee-Terrasse 2 } \\
\text { (II in Abb. 5) }\end{array}$ & ca. 556 m NN & $\begin{array}{l}\text { über Kaltenbach-Rinne (f in Abb. 5) Überlauf } \\
\text { heutiges Gelände westlich des Rückens Talholz }\end{array}$ & ca. 553 m NN \\
\hline $\begin{array}{l}\text { Untere Tüttensee-Terrasse } \\
\text { (III in Abb. 5) }\end{array}$ & ca. 536 m NN & $\begin{array}{l}\text { über Obereggerhausener Rinne (h in Abb. 5) } \\
\text { westlicher Ortsrand Marwang in die } \\
\text { Tiefenbach-Rinne (g in Abb. 5) }\end{array}$ & ca. 534 m NN \\
\hline
\end{tabular}

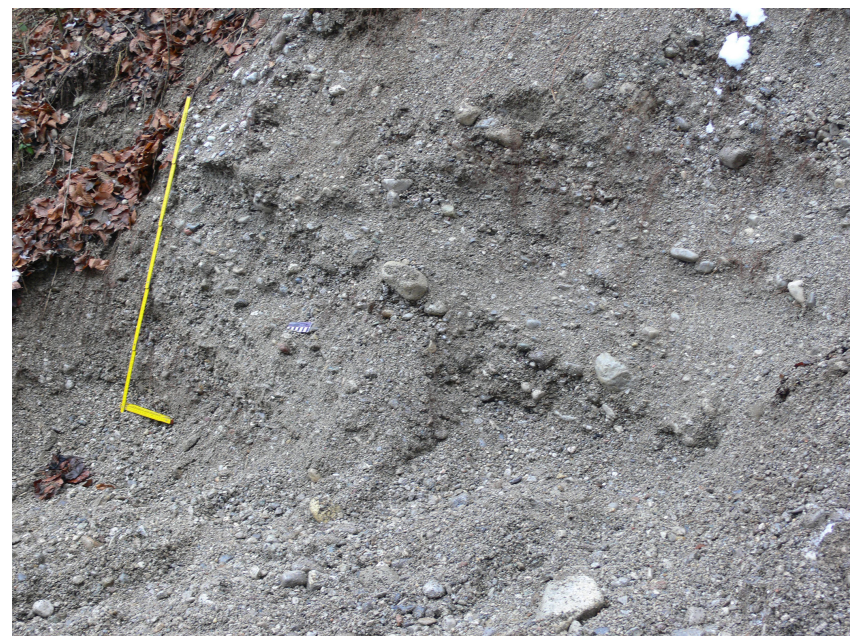

Abb. 10. Kies in der Materialentnahmestelle nördlich des Tüttensee-Auslaufs (Probenpunkt TS1; R=4542431, $\mathrm{H}=5301341$ ). Die Schichtung ist über die ganze Aufschlusshöhe zu erkennen. Deutlich ist auch die Schrägschichtung zu erkennen. Das Fallen der Schichten kann mit $20-30^{\circ}$ in Richtung Norden angegeben werden.

rassenkörper im Süden des Sees nur in seinen westlichsten Bereichen eine ebene Oberfläche. Im Osten ist seine Oberfläche hingegen weitgehend gewölbt und weist bei Lug einen fast dreieckigen Querschnitt auf. Der Übergang von dem Teil mit dreieckigem Querschnitt zu dem Teil mit der plateauartigen Oberfläche ist fließend.

Auffallend bei den westlichen Teilen dieser Terrasse sind im Aufschluss die sehr gut ausgewaschenen Kiese mit sehr gutem Rundungsgrad. Im Bereich nördlich des Tüttensee-Ausflusses sind in Materialentnahmestellen ausgeprägte Schrägschichtungen mit matrixfreiem Kies aufgeschlossen (Abb. 10, 11). Nach Süden und Osten hin nimmt der Feinkornanteil in den Sedimenten der UTT zu. Die Höhenlage des westlichen Teils der UTT korrespondiert mit dem Überlauf der Obereggerhausener Rinne (h in Abb. 5). Siehe auch Tabelle 1.

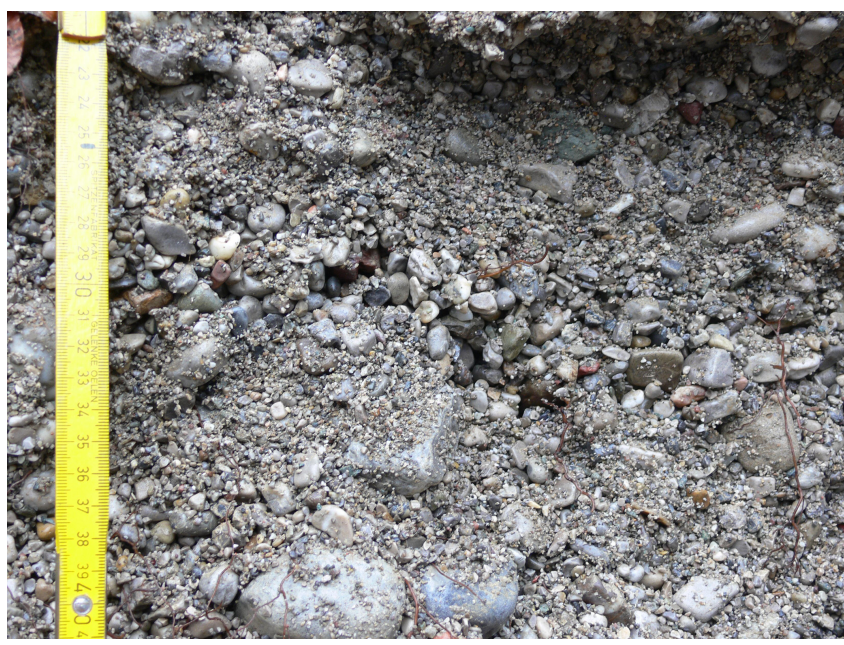

Abb. 11. Gleicher Aufschluss wie in Abb. 10. Der ca. $20 \times 20 \mathrm{~cm}$ große Ausschnitt lässt erkennen, dass dieser Kies grob geschichtet ist. Die mittelkiesige Lage, welche die Bildmitte ungefähr horizontal durchzieht, zeigt matrixfreie Räume zwischen den Geröllen.

\section{Der Rücken von Lug}

Der Rücken von Lug erstreckt sich in gekrümmter Form von Lug nach Nordosten ansteigend und folgt dem Seeufer, nach Norden umbiegend, bis zum Zulauf des Tüttensees, wo er steil abbricht. Dort erreicht der Hügel ( 549 m NN) eine Höhe von $23 \mathrm{~m}$ über dem Tüttensee-Spiegel.

Der südliche Teil der plateauartigen UTT ist mit dem Rücken von Lug über einen schmalen Geländerücken (,Flaschenhals") nach Osten hin verbunden. Im Gegensatz zur UTT hat der Rücken von Lug eine gerundete Oberseite, die zudem auch noch eine deutliche Höhendifferenz vom westlichen zum nördlichen Ende aufweist. Der Kiesanteil nimmt zu Gunsten des Feinkornanteils nach Osten ab.

\section{Der Hügel von Mühlbach}

Ca. $600 \mathrm{~m}$ östlich des Tüttensees, am Hang zwischen Mühlbach und Hiensdorf, liegt ein ungefähr Nord-Süd ausgerichteter Hügel von etwa $552 \mathrm{~m}$ NN Höhe (Abb. 8, 12). Er besteht, wie kleine Aufschlüsse zeigen, in seinem liegenden 


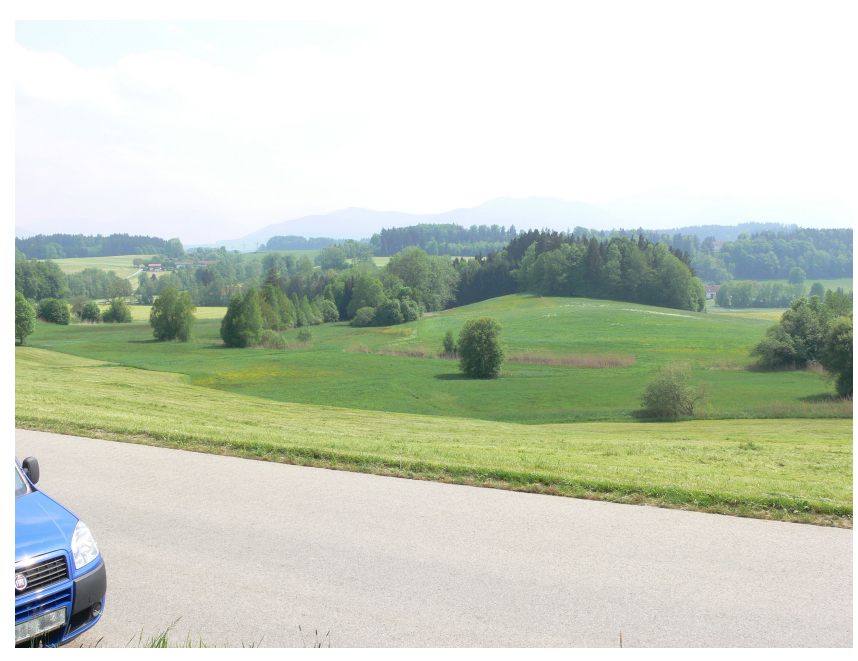

Abb. 12. Der Hügel von Mühlbach von der Straße HiensdorfMarwang aus gesehen. Blickrichtung nach Südsüdost. Der hellgrüne (gemähte) Wiesenstreifen an der Straße gibt ungefähr den Eisrand in der Grabenstätter Bucht zur Zeit der aktiven Hiensdorfer Rinne an dieser Stelle an (vgl. Abb. 20). Später, während der Entstehungszeit der obersten Tüttensee-Terrasse (OTT I in Abb. 8), war im Bildmittelgrund der Marwanger Eisrandstausee (vgl. Abb. 21), in dem sich die Sande und schräg geschichteten Kiese des Hügels von Mühlbach bildeten.

Bereich aus matrixgestütztem Diamikt. Dieser wird von deltageschichteten sandigen Kiesen, wie sie auch in OTT I+II auftreten, mit matrixfreien Groblagen überlagert. Sie zeigen ein Einfallen von ca. $30^{\circ}$ nach NW.

\section{Die Tüttensee-Senke}

Diese geomorphologische Einheit (T in Abb. 5 und 8) besteht aus dem heutigen Seebecken, seinen umliegenden anmoorigen Verlandungszonen sowie dem Tüttensee-Moor am östlichen Ende des Sees. Sie ist das zentrale Phänomen, an dem alle bisher beschriebenen Landschaftsteile des TüttenseeKomplexes anknüpfen. Die Seefläche des Tüttensees selbst ist birnenförmig und SE-NW ausgerichtet. Das Seebecken ist etwa $17 \mathrm{~m}$ tief (Grimminger, 1987) und zeigt eine asymmetrische, schrägkonische Tiefengeometrie, wobei der nordwestliche Bereich des Sees am tiefsten ist. Insgesamt setzt sich die Hangneigung der dem See zugewandten umgebenden Hänge im Seebecken fort.

Ungefähr $50 \mathrm{~m}$ östlich des Tüttensees liegt eine weitere Senke ( $\mathrm{T}^{\prime}$ in Abb. 8), die zusammen mit dem Tüttensee ,die liegende Acht" bei Gareis (1978:67) ergibt. Diese Senke ist von einem Moor ausgefüllt, das dem Tüttensee Wasser zuführt. Sie wird von den Hängen der OTT I+II, dem Rücken von Lug, dem Hügel von Mühlbach und dem diese beiden Hügel verbindenden Geländewulst allseits eingerahmt. Nur der Zulauf in den Tüttensee durchbricht den Ring der diese Senke umgebenden Sedimente.

\subsubsection{Das Gebiet von Chieming - Aufham - Laimgrub - Stöttham}

Zwischen Chieming und Stöttham sind Kiese, Sande und erratische Blöcke verbreitet. Im Gelände sind auffällig viele Senken erkennbar. Die bedeutendsten sind die „Wolfsgrube" $(\mathrm{R}=4540366, \mathrm{H}=5306371)$ im Ortskern von Chieming, der Pfeffersee $(\mathrm{R}=4540142, \mathrm{H}=5305741)$ und das Schwarzelmoos $(\mathrm{R}=4539672, \mathrm{H}=5306576)$. Letzteres ist mit einem bis zu $6 \mathrm{~m}$ mächtigen Übergangsmoor gefüllt (Schmeidl, 1977:229). Ca. $30 \mathrm{~m}$ westlich davon befindet sich parallel zum Chiemsee-Ufer eine wallartige Struktur $(\mathrm{R}=4539622, \mathrm{H}=5306528)$, deren sedimentologische Beschreibung bei Ganss (1977:184) auf eine Oserbildung schließen lässt.

Im DGM (Abb. 3) hebt sich diese generell nach Westen geneigte Eiszerfallslandschaft deutlich von dem nach Osten geneigten Kiesfächer ab, der sich östlich von Chieming in Richtung Laimgrub erstreckt. In diese Schotterfläche ist die Lohbach-Rinne ( $m$ in Abb. 5) eingetieft. Von Aufham kommend, mündet die Kaltenbach-Rinne (f in Abb. 5) in das Chieminger Siedlungsgebiet. Das Terrassenniveau der Hiensdorfer Rinne (d in Abb. 5) ist zwischen Aufham und Chieming von der Kaltenbach-Rinne zerschnitten, wie in Abb. 3 und 5 deutlich zu sehen ist.

Beim Punkt $\mathrm{R}=4541113, \mathrm{H}=5305999$ westlich Aufham standen zum Zeitpunkt der Begehung in einer Baugrube auf dem Niveau der Hiensdorfer Rinne bis in ca. 4,5 m Tiefe deutlich horizontal geschichtete, schlecht sortierte Kiese mit Steinen und Blöcken an.

\subsection{Lithofaziesuntersuchungen}

Die Aufschlussverhältnisse rund um den Tüttensee sind recht unterschiedlich. Neben zahlreichen, zum Teil noch im Abbau befindlichen Materialentnahmestellen, vor allem in der OTT I+II, bieten einige aufgelassene Gruben sowie Straßenaufschlüsse sehr gute Untersuchungsmöglichkeiten. An einigen Stellen hinterließen umgestürzte Wurzelteller tiefe Krater, die mit dem Spaten weiter vertieft wurden. In diesen Proben mag Bodenbildung die Rundung leicht beeinflusst haben. Daneben konnten mit dem Spaten an einigen Stellen im lockeren Material leicht Schürfgräben bis unter den Bodenhorizont zur Beprobung angelegt werden. Tabelle 2 bietet eine Übersicht über die Lage und Aufschlussverhältnisse der Lokationen, an denen Korngrößenuntersuchungen durchgeführt wurden.

Die Analysedaten der vier zu unterscheidenden Lithologien der klastischen Sedimente im Bereich des TüttenseeKomplexes sind in Abb. 13 dargestellt. Aus diesen Analysen und den Geländedaten entstand die Karte der Lithologien des Tüttensee-Komplexes (Abb. 14). 

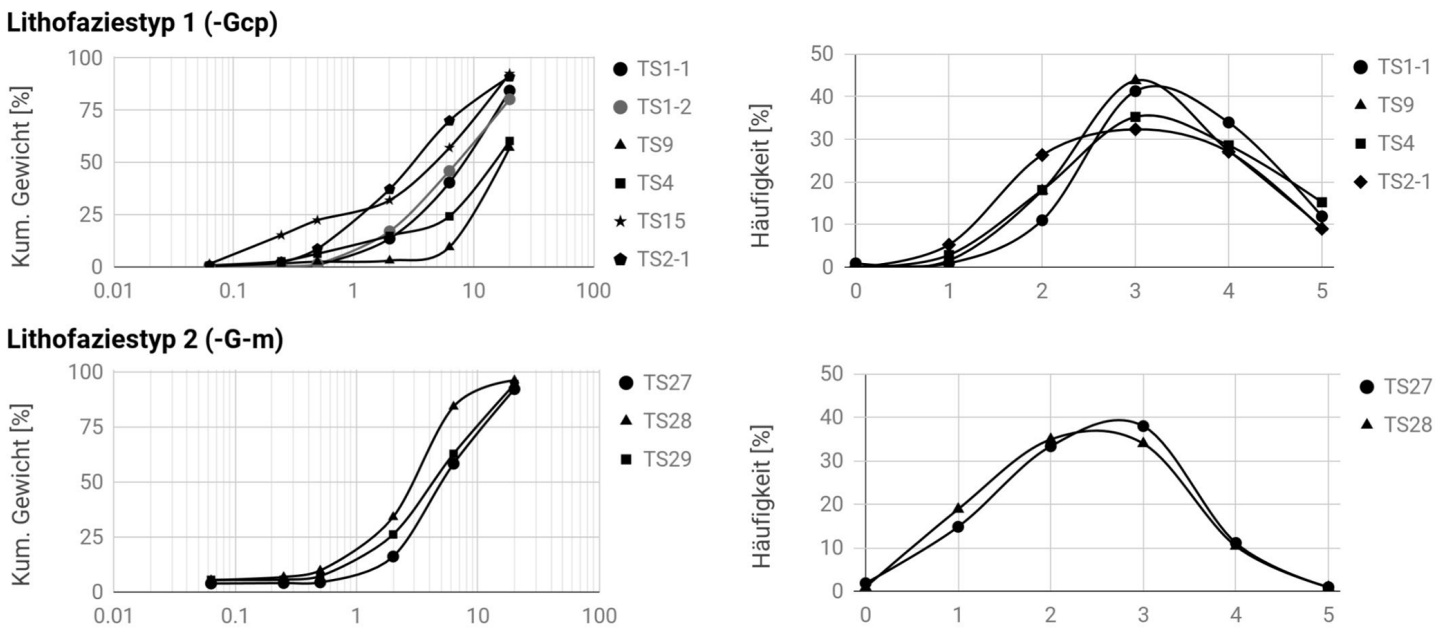

Lithofaziestyp 3 (gGm bis -G-m)
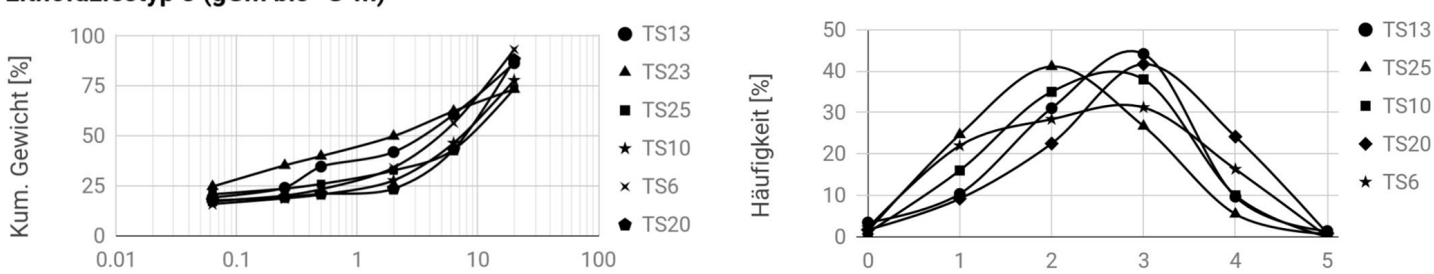

Lithofaziestyp 4 (Dm)
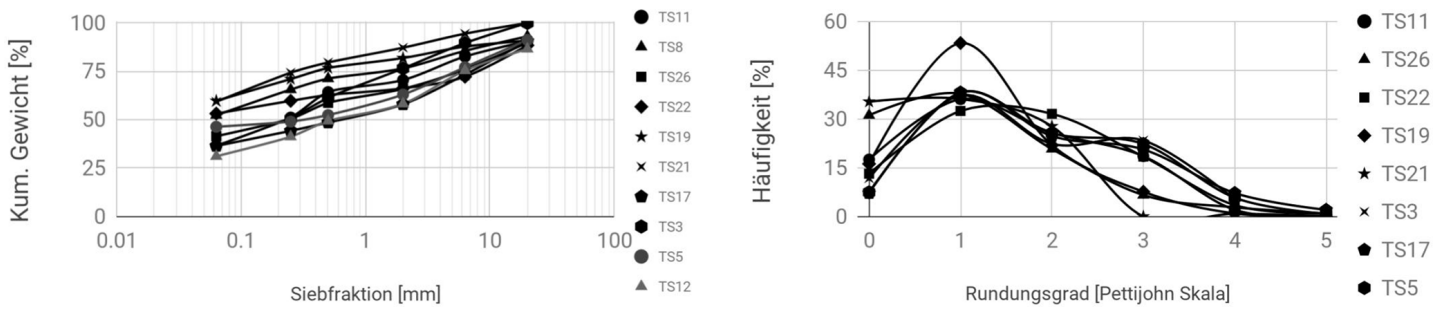

Abb. 13. Ergebnisse der sedimentologischen Analyse, Korngrößenspektrum und Rundungsgrad der einzelnen lithologischen Typen. Datenverfügbarkeit: Huber et al. 2019a, b). Lithofaziestyp 1=Schräggeschichtete, gradierte, gut gerundete, korngestützte Kiese; Lithofaziestyp $2=$ Undeutlich geschichtete, leicht bindige, gut gerundete, korngestützte Kiese; Lithofaziestyp 3: Ungeschichtete, stark bindige, matrixreiche Kiese; Lithofaziestyp 4: Tonige, schlecht sortierte, matrixgestützte Diamikte.

\subsubsection{Lithofaziestyp 1: Schräggeschichtete, gradierte, gut gerundete, korngestützte Kiese (-Gcp)}

Die Sedimente der Oberen Tüttensee-Terrasse und von Teilen der Unteren Tüttensee-Terrasse bestehen ausschließlich aus auffällig planar schräg geschichteten Kiesen, die zusätzlich durch das fast völlige Fehlen eines Feinkornanteiles gekennzeichnet sind. Die Schichtung im Zentimeter- bis Dezimeterbereich wird durch einen ausgeprägten Korngrößenwechsel deutlich. An einigen Aufschlüssen konnten wir so mehrere Schichtfolgen beobachten, die eine gut ausgeprägte, invers gradierte Schichtung aufweisen, wobei die Mächtigkeit der einzelnen Schichten zwischen 5 und $20 \mathrm{~cm}$ liegt. Zum Teil enden die Schichtfolgen im Hangenden mit einer markanten Block- bzw. Pflasterlage.

Die überwiegend kalkigen Komponenten sind gut bis sehr gut gerundet und liegen überwiegend im Mittel- bis Grob- kiesbereich. Es kommen aber auch sandige Einschaltungen vor. Neben den vorherrschenden kalkigen Komponenten fanden wir ein buntes Spektrum aus kristallinen Komponenten sowie vereinzelt gut erhaltene Großforaminiferen aus dem Helvetikum.

Auffällig ist das Auftreten von matrixfreien Grobkiesen (Openwork Gravel sensu Reineck und Singh, 1973), die große Hohlräume zwischen den sehr lose gepackten Körnern zeigen. In der Korngrößenanalyse zeigt sich stets ein sehr geringer Feinkornanteil (Silt und Ton), der meist unter 1\% liegt. In basalen Profilbereichen kann der Anteil etwas höher liegen und zeigt so den Übergang zu einem anderen Faziestyp an. Dominant sind dagegen stets die Gewichtsanteile der Kiesfraktion, die zwischen ca. $63 \%$ und $97 \%$ liegen. Die Körner aus diesem Faziestyp sind auf der Pettijohn-Skala überwiegend angerundet bis gut gerundet. Sowohl die Run- 


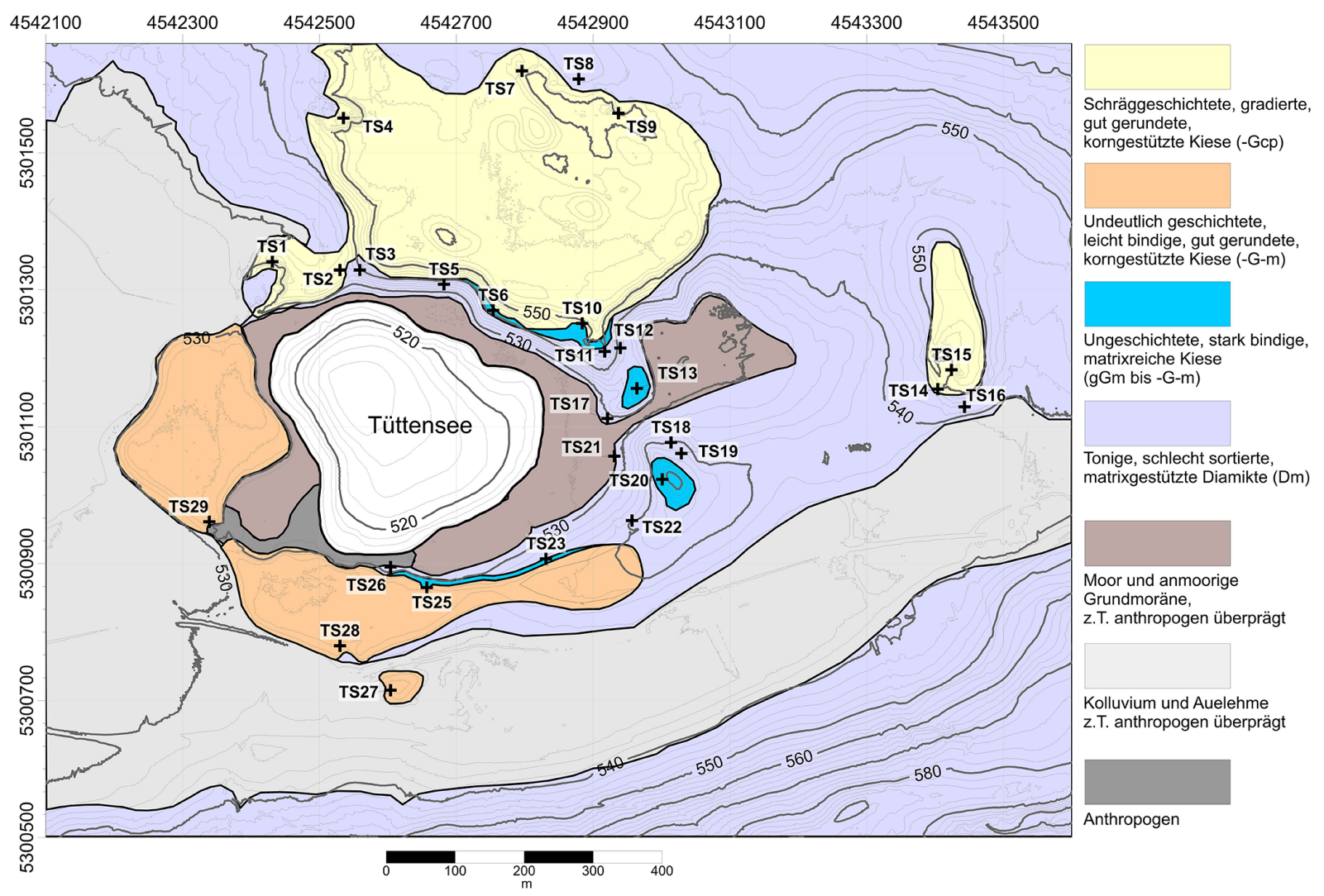

Abb. 14. Karte der Lithologien des Tüttensee-Komplexes und Lage der Probenpunkte. Geobasisdaten @ Bayerische Vermessungsverwaltung.

dung als auch die Sortierung der Komponenten belegen eine vergleichsweise hohe texturelle Reife der Kiese.

An einigen Stellen (TS1, TS4, TS15 in Abb. 14) konnte das Einfallen (z.B. Abb. 10) bestimmt werden. Demnach fallen die Schichten mit etwa 20 bis $30^{\circ}$ in nördlicher Richtung. Das sehr lockere und meist gut sortierte Sediment findet vor Ort als Bau- und Schüttgut Verwendung, wovon zahlreiche Materialentnahmestellen entlang des nördlichen Randes der OTT I+II zeugen. Diesen Sedimenttyp konnten wir an den Lokationen TS1, TS2, TS4, TS9 sowie TS15 (Tabelle 2) beproben und an den Lokationen TS7 und TS14 im Gelände belegen.

Nach der Klassifikation von Keller (1996) können diese Sedimente als gerundeter, planar schräg geschichteter Kies (-Gcp) angesprochen werden. Angesichts der beobachteten Sedimenteigenschaften interpretieren wir diese Sedimente als Deltabildungen. Vergleichbare Deltabildungen wurden von zahlreichen Autoren im glazilakustrinen Kontext beschrieben (Martini, 1990; Nemec et al., 1999; Kostic et al., 2005; Russell, 2007).

\subsubsection{Lithofaziestyp 2: Undeutlich geschichtete, leicht bindige, gut gerundete, korngestützte Kiese (-G-m)}

Dieser Ablagerungstyp dominiert die westlichen und südwestlichen Bereiche der Unteren Tüttensee-Terrasse. Die hier ebenfalls überwiegend kalkigen Komponenten sind gut gerundet und liegen meist im Fein- bis Mittelkiesbereich. Die Kiese wirken im Gelände im Vergleich zu dem vorab beschriebenen Sedimenttyp deutlich bindiger und feinkörniger, ihr Ton- und Siltanteil liegt bei etwa 4-5 Gewichtsprozent. Der dominante Kiesanteil beträgt zwischen $66 \%$ und $84 \%$. Im Aufschluss erscheinen diese Kiese undeutlich geschichtet. Das Einfallen der Schichtung konnte daher nicht näher bestimmt werden, sie scheint jedoch bei TS27 (Abb. 14) nach Süden zu weisen. Auffällig sind häufig anzutreffende, unregelmäßig eingestreute Grobkieskomponenten und Blöcke. Im Hangenden einiger Aufschlüsse (Abb. 14, Tabelle 2: TS27, TS29) kann man eine deutliche Anreicherung größerer Gerölle beobachten, die stellenweise als abschließende Blocklage auftreten. Die Längsachsen dieser Gerölle sind bevorzugt NE-SW orientiert eingeregelt. Die Körner in der Kiesfraktion sind überwiegend angerundet bis gerundet. Die texturelle Reife des Sediments ist damit gut, aber die Rundung weniger stark ausgeprägt als bei Lithofaziestyp 1 . 
Tabelle 2. Übersicht über die Koordinaten (Gauss-Krüger) und Aufschlussverhältnisse der beprobten Lokationen an denen Korngrößenanalysen durchgeführt wurden.

\begin{tabular}{lccl}
\hline Lokation & Rechtswert & Hochwert & Aufschlusstyp \\
\hline Lithofaziestyp 1 & & \\
\hline TS1 & 4542431 & 5301341 & Kiesgrube \\
TS2 & 4542530 & 5301329 & Schurf \\
TS4 & 4542535 & 5301551 & Kiesgrube \\
TS9 & 4542937 & 5301558 & Kiesgrube \\
TS15 & 4543424 & 5301183 & Kiesgrube \\
TS14 & 4543404 & 5301155 & Kiesgrube \\
\hline Lithofaziestyp 2 & & \\
\hline TS27 & 4542604 & 5300715 & Kiesgrube \\
TS28 & 4542530 & 5300780 & Kiesgrube \\
TS29 & 4542339 & 5300961 & Kiesgrube \\
\hline Lithofaziestyp 3 & & \\
\hline TS13 & 4542964 & 5301156 & Wurzelteller/Schurf \\
TS23 & 4542831 & 5300907 & Straßenanschnitt/Schurf \\
TS25 & 4542657 & 5300865 & Kiesgrube \\
TS10 & 4542884 & 5301251 & Wurzelteller/Schurf \\
TS6 & 4542754 & 5301270 & Wurzelteller/Schurf \\
TS20 & 4543001 & 5301023 & Schurf \\
\hline Lithofaziestyp 4 & & \\
\hline TS11 & 4542917 & 5301210 & Wurzelteller/Schurf \\
TS12 & 4542940 & 5301215 & Wurzelteller/Schurf \\
TS8 & 4542879 & 5301608 & Schurf \\
TS26 & 4542604 & 5300895 & Straßenanschnitt \\
TS22 & 4542957 & 5300963 & Schurf \\
TS19 & 4543029 & 5301061 & Wurzelteller/Schurf \\
TS21 & 4542931 & 5301057 & Schurf \\
TS17 & 4542921 & 5301112 & Bachbett \\
TS3 & 4542559 & 5301329 & Wurzelteller/Schurf \\
TS5 & 4542682 & 5301308 & Wurzelteller/Schurf \\
\hline & & & \\
\hline
\end{tabular}

Nach der Klassifikation von Keller (1996) können diese Sedimente als undeutlich geschichtete, leicht bindige, gut gerundete, korngestützte Kiese (-G-m) gekennzeichnet werden. Aufgrund der lithofaziellen Charakteristik lassen sich diese Sedimente nach Miall (1977) sowie Keller (1996) als Barrensediment eines Flußsystems einordnen.

\subsubsection{Lithofaziestyp 3: Ungeschichtete, stark bindige, matrixreiche Kiese ( $\mathrm{gGm}$ bis -G-m)}

Insbesondere in den dem See zugewandten mittleren Höhenlagen, finden sich stark bindige, tonreiche, kiesige Sedimente, die in den wenigen Aufschlüssen keine Schichtung erkennen lassen. Überwiegend kalkige Komponenten aus dem Fein- bis Grobkiesbereich dominieren die Siebprobe mit über $50 \%$. Häufig ist ein, im Vergleich zu den Lithofaziestypen 1 und 2, erhöhter Sandanteil zu erkennen. Kennzeichnend ist der stark erhöhte Ton- und Siltanteil, der zwischen $16 \%$ und $25 \%$ liegt.

Die Rundung der Körner dieses Sedimenttyps ist nicht gut ausgeprägt, sie sind meist eckig oder kantengerundet bis angerundet. Gerundete oder gut gerundete Körner kommen nur in untergeordneten Anteilen vor. Die texturelle Reife ist daher nicht sehr gut ausgeprägt.

In Lokation TS25 (Abb. 14) bildet dieser Faziestyp das Liegende der darüber liegenden abbauwürdigen Kiese. Diese Position über den Sedimenten des Lithofaziestyps 2 wird auch durch die Zusammenstellung der Probenpunkte im Kartenbild deutlich.

Nach Keller (1996) können diese Sedimente als ungeschichtete, stark bindige, matrixreiche Kiese (gGm bis -G-m) klassifiziert werden. Wir interpretieren diese Sedimente als glazifluvial beeinflusstes bzw. verschwemmtes Moränenmaterial. Erwähnenswert ist Lokation TS25, da sie offensichtlich zeitweise als wilde Müllkippe genutzt wurde, in der wir poröse, grünlich dunkelgraue Schlacken fanden. Solche wurden von Ernstson et al. (2010:79) als Impaktgestein (,impactites") angesprochen.

\subsubsection{Lithofaziestyp 4: Tonige, schlecht sortierte, matrixgestützte Diamikte (Dm)}

In den tiefsten untersuchten Hanglagen, der den Tüttensee umgebenden Hügel, finden sich häufig sehr bindige, stark tonig-siltige Kiese bzw. kiesige Tone. Das gut knetbare, tonig-kiesige Material ist völlig ungeschichtet, unsortiert und weist eine deutlich matrixgestützte Textur auf. Am Ostufer des Tüttensees stehen diese tonigen Sedimente oberflächlich an und bilden einen oft unangenehm rutschigen, lehmigen Untergrund. An diesen Straßenanschnitten lassen sie sich auf mindestens 8 bis $10 \mathrm{~m}$ Mächtigkeit verfolgen. Die Siebprobe zeigt stets einen sehr hohen Silt- und Tonanteil zwischen $36 \%$ und $60 \%$. Daneben sind die Sand- und Kiesfraktionen in etwa gleichen Anteilen vertreten. Die Rundung der überwiegend kalkigen Kiesfraktion ist meist sehr schlecht ausgeprägt, es dominieren eckige Komponenten. Kompaktion konnte nicht festgestellt werden. Nur an Lokation TS17 fanden wir starke Anzeichen von Verfestigung.

Diese Sedimente können nach Keller (1996) als matrixgestützte Diamikite klassifiziert werden. Aufgrund dieser Eigenschaften, stellen diese Sedimente wohl Grundmoränenmaterial dar.

\section{Diskussion}

Die Abschmelzgeschichte des östlichen ChiemseeGletschers entwickelte sich in Phasen, analog zum übrigen Inn-Chiemsee-Gletschergebiet (Abb. 2). Nur in den Bereichen mit größeren Toteisvorkommen gab es lokale Sonderformen, zu denen der Tüttensee-Komplex zu zählen ist. Die während des Eisabbaus entstandenen Entwässerungsrinnen werden hier in ,ältere“ und ,jün- 
gere" Rinnen unterteilt. Die jüngeren Rinnen sind direkt im Zusammenhang der Ablagerung der Sedimente des Tüttensee-Komplexes zu sehen.

\subsection{Die älteren Schmelzwasserrinnen}

Während des Kirchseeoner Stadiums (Abb. 2) entwickelte sich in unserem Arbeitsgebiet zuerst der zentrifugal angelegte Teil der Traunstorfer Rinne (a in Abb. 5; Abb. 15). Etwas später erweiterte sich diese Rinne nach Süden. Zu der Zeit reichte auch die Axdorfer Rinne (l in Abb. 5; Abb. 16) bis in das Arbeitsgebiet.

Die zum Ebersberger Stadium (Abb. 2) gehörende Wolkersdorfer Rinne (b in Abb. 5; Abb. 17) war dagegen bereits eine rein peripher entwässernde Rinne. Sie umfloss bei Nußdorf den Eislobus von Eglsee, dessen östliches Ufer von einem Moränenbogen bei Nußdorf gebildet wurde. Dieser Nußdorfer Moränenbogen deutet darauf hin, dass der Rand des Eislobus von Eglsee bei Nußdorf über längere Zeit stationär war. Bei Vachendorf bildete sich in einem Moränenzwickel ein kleiner Eisrandsee (Abb. 17) der sich bis etwa Axdorf erstreckte. Ganss (1977) fand in diesem Gebiet Seetone, Bayberger (1882) erwähnt ein abbauwürdiges Lehmlager bei Axdorf. Hier sind noch heute am östlichen Ortsende Seetone und Torfe leicht zu ergraben (Albert Rosenegger, Axdorf, pers. Mitteilung, 2016). Ein Überlauf ermöglichte den Abfluss über die Axdorfer Rinne in das Traun-Tal.

Mit dem Eintreten des Ölkofener Stadiums (Abb. 2) etablierte sich die Bad Adelholzen-Erlstätter Rinne (c in Abb.5; Abb. 18) als größte Entwässerungsrinne. In Abb. 2 sind auch die analogen Schmelzwasserrinnen im Bereich des Inn- und des westlichen Chiemsee-Gletschers abgebildet. Innerhalb des Moränenbogens von Eglsee lag sicher auch noch während der älteren Phase der Bad Adelholzen-Erlstätter Rinne (c1 in Abb. 18) Toteis, wie spätwürmzeitliche Seetone unmittelbar nördlich Eglsee (Jerz, 1999) belegen. Ganss (1977) hat unmittelbar südlich von Eglsee ein Toteisloch in Abschlämmmassen kartiert. Heute ist die Eglsee-Hohlform weitgehend von Moorablagerungen unterschiedlicher Ausprägung ausgefüllt (Ganss, 1977). Toteis dürfte auch innerhalb des Moränenbogens von Tinnerting (Abb. 18) geblieben sein. Ganss (1977:180) hat diesen Lobus als „Kleinmodell glazialer Formenelemente" bezeichnet. Der Schmelzwasserabfluss durch die Axdorfer Rinne war versiegt.

Die Bad Adelholzen-Erlstätter Rinne nahm nun sowohl das Schmelzwasser aus der Bergener Bucht, (südlich des Kleierbergs; Abb. 15-25) als auch die vom Eisrand abfließenden Wassermassen auf. Zahlreiche Kiesgruben entlang des Bad Adelholzen-Erlstätter Tals ermöglichen heute den Abbau gut sortierter Kiese. Diese Kiese zeigen typische Strukturen von Braided-River- oder AnastomosingRiver-Sedimenten (Abb. 6) und belegen die glazifluviale Genese dieser Ebene. Blöcke von manchmal deutlich mehr als einem Kubikmeter Volumen in den Kiesen legen eine unmit- telbare Nachbarschaft des Eisrandes während der Kiesablagerung nahe.

Ein weiteres Abschmelzen der Eismassen hinter den Moränenzug nördlich von Laimgrub führte bei Eglsee zur Verlagerung der Bad Adelholzen-Erlstätter Rinne in Richtung Westen (Troll, 1924; c2 in Abb. 5), sodass hier ein breiter Schotterstrang entstand (Abb. 19). Die Kiesgruben nordwestlich von Laimgrub zeigen auch hier typische glazifluviale Kiese, wie sie die Bad Adelholzen-Erlstätter Rinne generell führt. Allerdings ist die durchschnittliche Korngröße deutlich geringer und gleichkörniger als weiter im Süden.

Südlich von Wipfing bei Vachendorf bildete sich am Ostende der Grabenstätter Bucht vermutlich ein Gletschertor, das sich immer weiter rückwärtig nach Südwesten, in den aus der Bergener Bucht über den Kleierberg reichenden Gletscher, verlegte (Abb. 20). Das führte zur allmählichen Einkerbung des Gletschers bis etwa Eckering. Damit war die Teilung des östlichen Chiemsee-Gletschers in einen stagnierenden Eislappen in der Grabenstätter Bucht nördlich des Kleierbergs und den Hauptteil des wohl noch aktiven Gletschers in der Bergener Bucht eingeleitet. Die freigesetzten Wassermassen bildeten schließlich die im Kartenbild trichterförmige Wipfinger Rinne ( $\mathrm{k}$ in Abb. 5). Diese Rinne mündete zuerst noch in die Bad Adelholzen-Erlstätter Rinne. Mit dem Einsetzen der jüngeren Abschmelzphasen floss das Wasser der Wipfinger Rinne (anfänglich möglicherweise noch über das Eis der Grabenstätter Bucht) in die Hiensdorfer Rinne (d in Abb. 5), die entlang des Gletscherrandes innerhalb der Moränen des Ölkofener Stadiums weiter nach Nordwesten führte. Damit begann die Trockenlegung der Bad Adelholzen-Erlstätter Rinne.

Das weitere Abschmelzen der Eiszunge in der Bergener Bucht brachte die obertägige Schmelzwasserzufuhr in die Bad Adelholzen-Erlstätter Rinne allmählich ganz zum Erliegen. Als das Eis so weit von der Bad AdelholzenErlstätter Rinne zurückgeschmolzen war, dass das Schmelzwasser primär westlich der Moränenwälle zwischen Aufham und Hiensdorf abfließen konnte, etablierte sich die Hiensdorfer Rinne vollständig. Der nördliche Rand der Hiensdorfer Rinne zwischen Hiensdorf und Marwang war durch die Moränenerhebungen gegeben, der Südrand bestand aus dem Rand des Grabenstätter Eislappens in der Grabenstätter Bucht. Das Schmelzwasser floss also entlang des Gletschereises und lagerte hier kiesiges Material ab. Dabei schmolz der Gletscherrand kontinuierlich nach Süden hin ab und schuf so den Raum für die Kames-Bildungen der Hiensdorfer Rinne an dieser Stelle.

Die Bad Adelholzen-Erlstätter Rinne bekam im Zuge dieser Entwicklung immer weniger Schmelzwasser und entwickelte sich zum Trockental. Die Hiensdorfer Rinne übernahm also zunehmend die Rolle der Hauptabflussbahn der Schmelzwässer des südöstlichen Chiemsee-Gletschers (Abb. 20). 


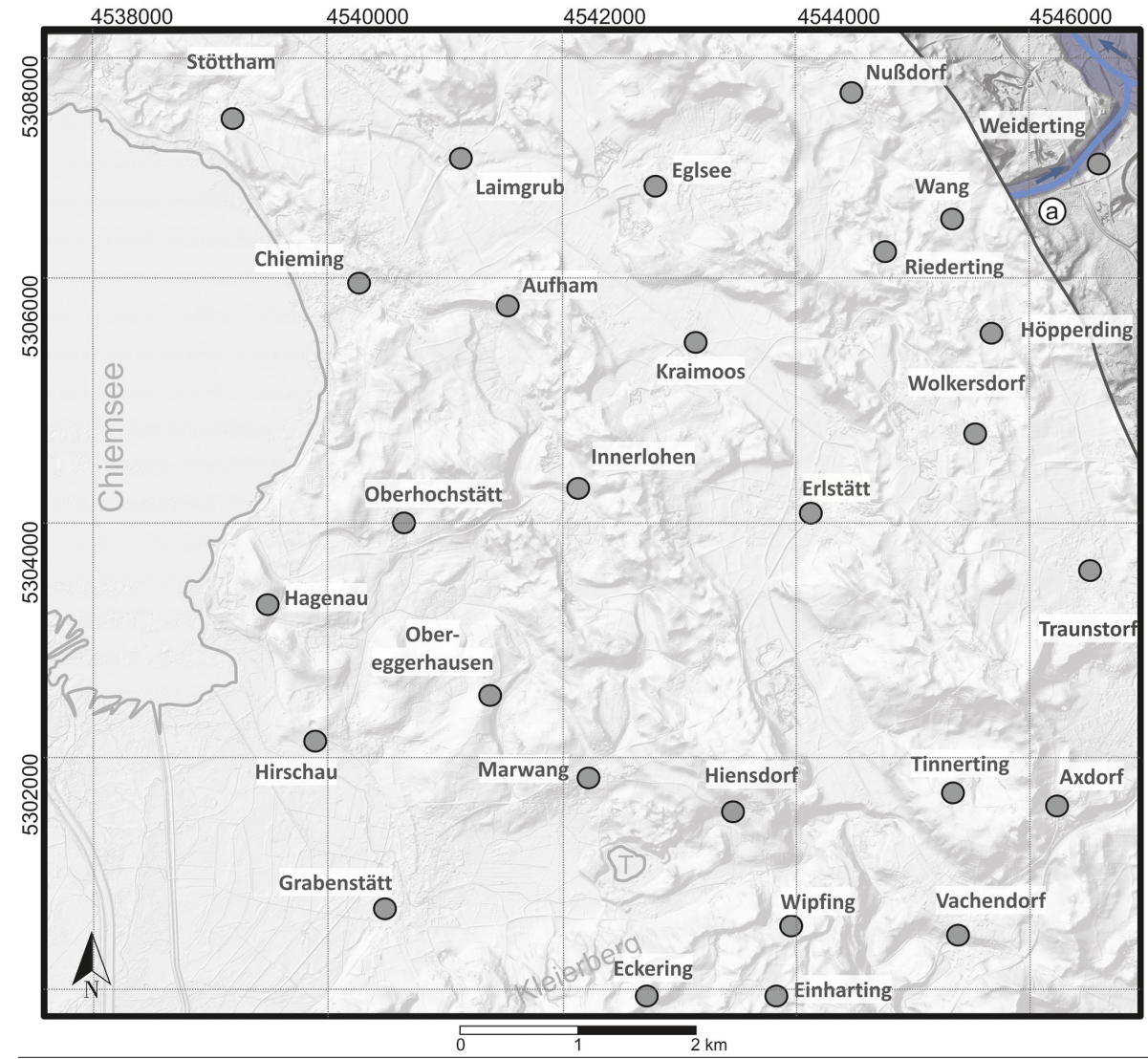

Abb. 15. Phase 1. Die im gezeigten Geländeausschnitt zuerst angelegte zentrifugale Rinne von Wang-Weiderting (vgl. a in Abb. 5), die sich später zur Traunstorfer Rinne (Abb. 16) entwickelt. Geobasisdaten (C) Bayerische Vermessungsverwaltung.

\subsection{Die jüngeren Schmelzwasserrinnen und die Entstehung des Tüttensee-Komplexes}

Der fortschreitende Eisabbau ließ die Gletscherränder weiter abschmelzen (Abb. 21). Dabei entwickelte sich zwischen Hiensdorf und Marwang, in einer Senke zwischen Moräne und Gletscherrand, der Marwanger Eisrandsee. So waren die Voraussetzungen für die Entstehung des TüttenseeKomplexes geschaffen, der sich deutlich von der umliegenden, sanft hügeligen Moränenlandschaft unterscheidet. Denn während die Tüttensee-Terrassen von schräggeschichteten Deltakiesen dominiert werden, die praktisch keinen Feinkornanteil aufweisen, sind sie von Grundmoränenablagerungen umgeben (Ganss, 1977). Diese Diamikte sind das stratigraphisch älteste Sediment des Tüttensee-Komplexes (Abb. 14) und zweifellos in unmittelbarer Nähe des Eisrandes abgelagert worden. Ein Horizont aus verschwemmtem, wenig umgelagertem Moränenmaterial, der die Grundmoräne am Ufer des Tüttensees überlagert (Abb. 14), zeigt einen Wandel des Ablagerungsmilieus an, der in den jüngeren Sedimenten der Tüttensee-Terrassen offensichtlich wird.

\subsubsection{Die Oberen Tüttensee-Terrassen mit den dazu gehörigen Abflussrinnen}

Die Deltakiese der Oberen Tüttensee-Terrassen zeigen das normale Sedimentationsbild von Verfüllungen von Eisrandseen durch Gerinne mit rasch und stark schwankender Wasserführung (Schmelzwasserandrang im Tagesrhythmus), und sich stetig verlegenden Mündungsbereichen sowie starker Sedimentführung. Die Feinanteile werden dabei oberflächennah als Schweb im Wasserkörper transportiert und bilden dann das Bottom Set. Bei kleineren Wasserkörpern, wie dem Marwanger Eisrandsee, gehen sie über den Abfluss verloren.

Diese von Schmelzwasser über das Eis der Grabenstätter Bucht transportierten Moränenkiese bauten so im Marwanger Eisrandsee ein Kames-Delta auf, das der heutigen Oberen Tüttensee-Terrasse (I in Abb. 5; OTT I in Abb. 8) entspricht. Den Abfluss des Sees bildete die kleine Marwanger Rinne (e in Abb. 5; Abb. 21). Dazu passend korrespondiert die Höhenlage der OTT I mit der Überlaufhöhe in die Marwanger Rinne (Tabelle 1).

Der weitere Eisabbau ermöglichte die westliche Verlagerung des Abflusses des Eisrandsees in die tiefer gelegene Kaltenbach Rinne (f in Abb. 5; Abb. 22). Die dadurch bedingte Senkung des Eisrandseespiegels ließ die Oberste Ter- 


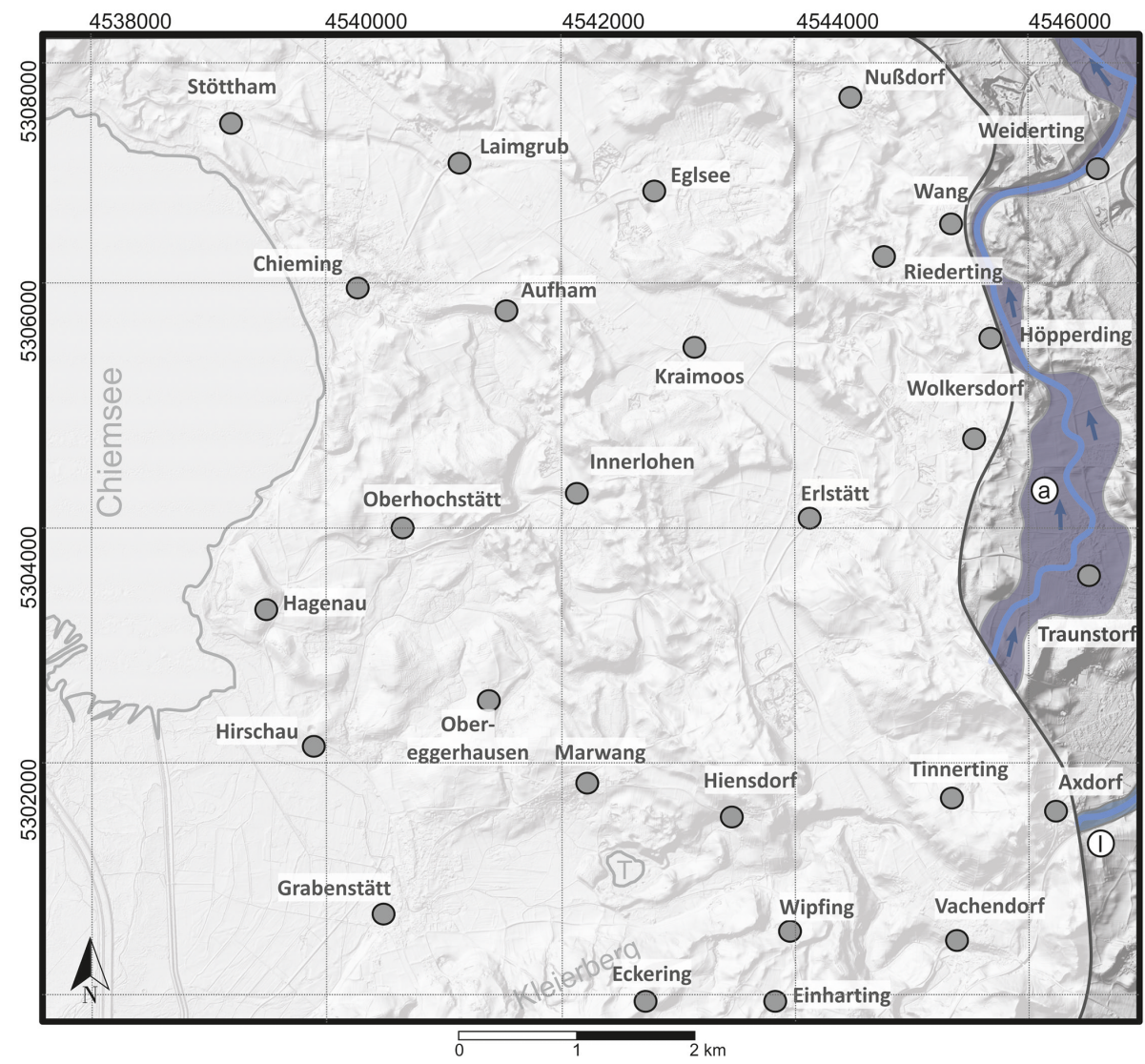

Abb. 16. Phase 2. Traunstorfer Rinne (a in Abb. 5). Von Wang über Höpperding bis Traunstorf entwickelt sich eine periphere Entwässerungsrinne, die weiterhin über das zentrifugale Tal von Wang-Weiderting in die Traun entwässert. Im Süden tritt die Rinne von Axdorf (1 in Abb.5) in Erscheinung. Geobasisdaten ( Bayerische Vermessungsverwaltung.

rasse (OTT I) trockenfallen und es bildete sich die untere der beiden Oberen Tüttensee-Terrassen (OTT II in Abb. 8), ebenfalls als Kames-Delta. Die Höhenlage der OTT II korrespondiert mit der Höhenlage des Beginns der Kaltenbach-Rinne. Der weitere Ablauf des Schmelzwassers findet nach kurzem Umweg wieder im Bett der Hiensdorfer Rinne statt, wo sich die Kaltenbach Rinne aber kräftig einschneidet. Bei Aufham wird sie nach Westen umgelenkt und schüttet dort in das Eiszerfallsgebiet von Chieming.

Zeitgleich lagerte sich offenbar vor und in einer größeren Gletscherspalte südlich von Hiensdorf ein Kames-Delta ab, das nach dem Abschmelzen des Eises als Hügel von Mühlbach (Mü in Abb. 8) stehen blieb. Die Höhe des Hügels von Mühlbach ist mit $555 \mathrm{~m} \mathrm{NN}$ fast identisch mit der Höhenlage von OTT II. Die von uns gefundenen Deltasedimente am Hügel von Mühlbach belegen diesen Eisrandsee. Dieser Hügel ist von Ganss (1977) in der geologischen Karte irrtümlich als Moränenzug interpretiert und von Gareis (1978) als von Schmelzwässern aus der Grundmoräne herauspräparierter Umlaufberg angesprochen worden.

Ein beträchtlicher Teil des Sedimenteintrags dürfte zu dieser Zeit über die Wipfinger Rinne ( $\mathrm{k}$ in Abb. 5) erfolgt sein.
Die Steilheit dieser Rinne spricht für hohe Strömungsgeschwindigkeiten und entsprechende Sedimentfracht. Weitere Sedimentzufuhr erfolgte aus dem sich immer tiefer nach Süden einschneidenden heutigen Mühlbachtal, das noch Schmelzwässer aus der Bergener Bucht abführte und so die Bad Adelholzen-Erlstätter Rinne erodierte (Abb. 21, 22). Dies wird durch die nordwestliche Fallrichtung der Deltasedimente des Hügels von Mühlbach gestützt.

Die Schichtung der Deltasedimente der OTT I+II fällt dagegen in nordöstlicher Richtung, was teilweise durch die typischen radialen Abflussstrukturen innerhalb eines Deltakegels erklärt werden kann. Die Sedimentzufuhr erfolgte aus südwestlicher Richtung, vom angrenzenden, nur noch relativ niedrigen Gletscherrest in der Grabenstätter Bucht. Dafür spricht auch die scharf abgegrenzte, südwestliche, obere Terrassenkante (OTT II) am Tüttensee, die in etwa die ehemalige nördliche Eisgrenze nachzeichnet. Dies stützt die Interpretation der Kiese der OTT II als Sedimente eines Kames-Deltas.

Die Geröllfracht der Schmelzwässer bestand aus eistransportiertem Material der ehemals mächtigen Eisdecke, aus Material des örtlich erodierten Untergrundes sowie aus den Resedimenten der älteren Abflussrinnen. 


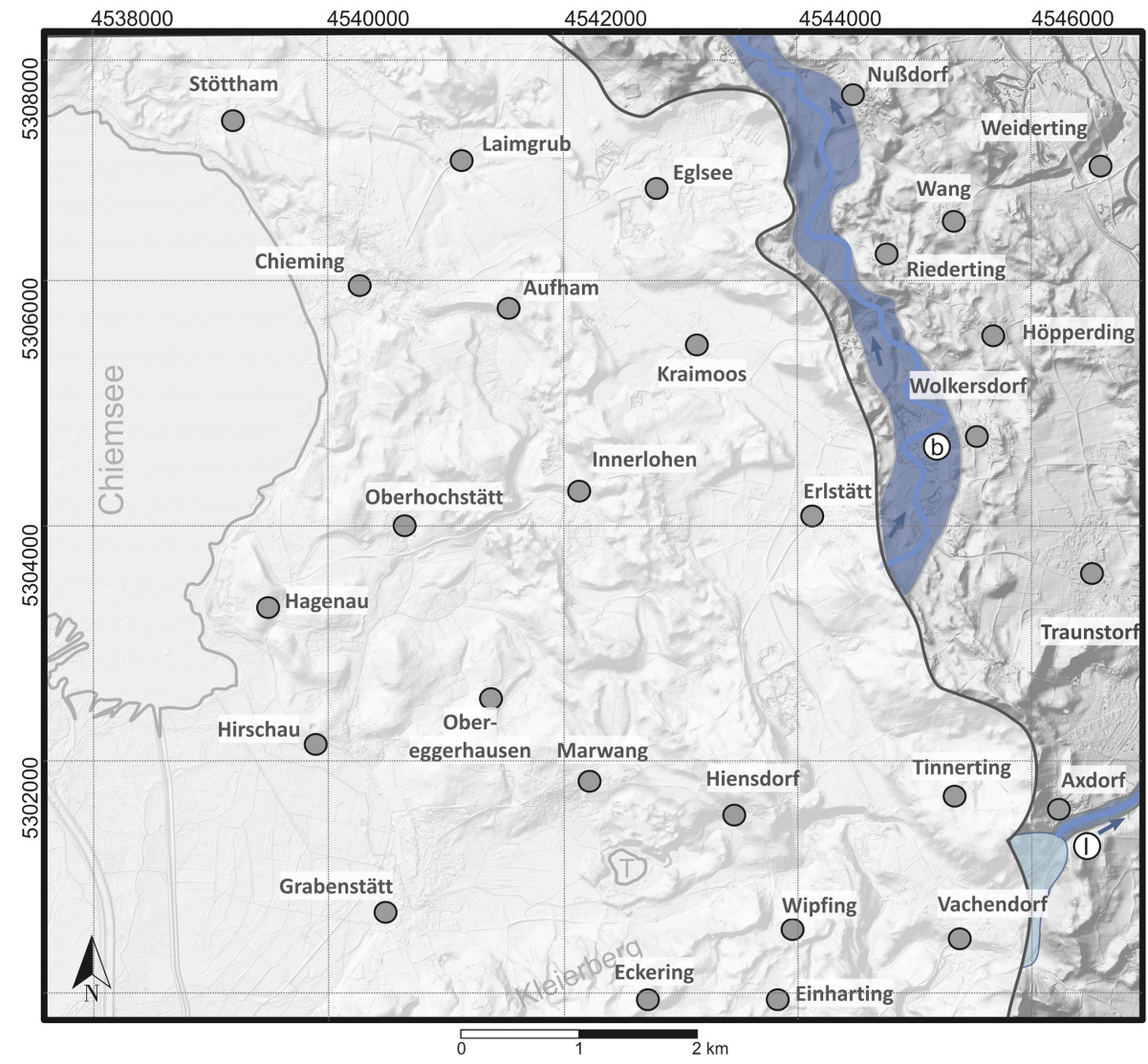

Abb. 17. Phase 3. Die peripher entwässernde Rinne von Wolkersdorf (b in Abb. 5). Die Rinne von Traunstorf-Wang-Weiderting führt kein Schmelzwasser mehr. Südlich von Axdorf setzen sich in einem kleinen Eisrandstausee Tone ab, der Abfluss erfolgt weiterhin über die Axdorfer Rinne (1 in Abb. 5). Die Eislappen von Eglsee und Tinnerting zeichnen sich ab. Geobasisdaten () Bayerische Vermessungsverwaltung.

Durch die hohen Schüttungsraten dieser Zuflüsse, verlagerte sich das Delta stetig weiter nach Norden und Westen. Dadurch verengte sich das Randbecken, bis es nahezu verlandete. Vereinzelte Eisblöcke wurden vom Tüttensee-Delta umschottert (evtl. sogar begraben) und führten zur Bildung der bereits von Ganss (1977:185) und Gareis (1978:67) beobachteten Toteislöcher auf den Oberen Tüttensee-Terrassen (Abb. 8). Die Oberflächen dieses ehemaligen Deltas geben in etwa das Niveau des jeweils dazugehörigen Eisrandsees wieder.

\subsubsection{Die Untere Tüttensee-Terrasse, der Rücken von Lug und die Tiefenbach-Rinne}

Die Entstehung der Unteren Tüttensee-Terrasse wurde zuvor durch eine weitere Verlegung des Gletscherrandes nach Süden eingeleitet. Im Verlauf dieser Abschmelzvorgänge verlagerte sich auch der Marwanger Eisrandstausee nach Westen in tiefer gelegene Bereiche (Abb. 23), und entwässerte über die ebenfalls tiefer gelegene Obereggerhausener Rinne (h in Abb. 5) und in ihre nördliche Fortsetzung, die Tiefenbach-Rinne (g in Abb. 5). Diese Rinne ermöglichte den weiteren Abfluss aus dem Eisrandsee über Oberhochstätt in den damaligen Chiemsee. Ihre Mündung in den endeiszeitlichen Chiemsee liegt dort heute $8 \mathrm{~m}$ über dem ChiemseeWasserspiegel. Die Kaltenbach-Rinne fiel mit dem Eintreten der Absenkung des Seespiegels trocken.

Direkt unter dem Tüttensee hat Papadeas (1972) im Molasse-Untergrund eine markante Mulde festgestellt, die an dieser Stelle eine größere Eismächtigkeit ermöglichte, was letztlich zur Bildung von Toteis führte. Zwei dieser Toteiskörper waren das Tüttensee-Toteis und sein kleinerer östlicher Nachbar (Gareis, 1978). Beide Toteiskörper grenzten im Norden an die bis dahin abgelagerten Sedimente der Oberen Tüttensee-Terrassen.

In der breiten Trennungsspalte zwischen Toteis und Gletscher floss das Schmelzwasser und bildete die Untere Tüttensee-Terrasse (UTT in Abb. 8; III in Abb. 5) als KamesBildung aus. An der Mündung der Spalte in den Eisrandsee bildete sich ein Delta (Abb. 23). Das Delta belegt somit die südöstliche Begrenzung des Eisrandstausees zwischen Tüttensee-Toteis und dem Eis der Grabenstätter Bucht.

Bei Obereggerhausen findet man im Bett des Eggerhausener Bachs fast reine, hellgraue Tone (siehe auch Ganss, 1977:177). Diese Tone belegen die nördliche Ausdehnung 


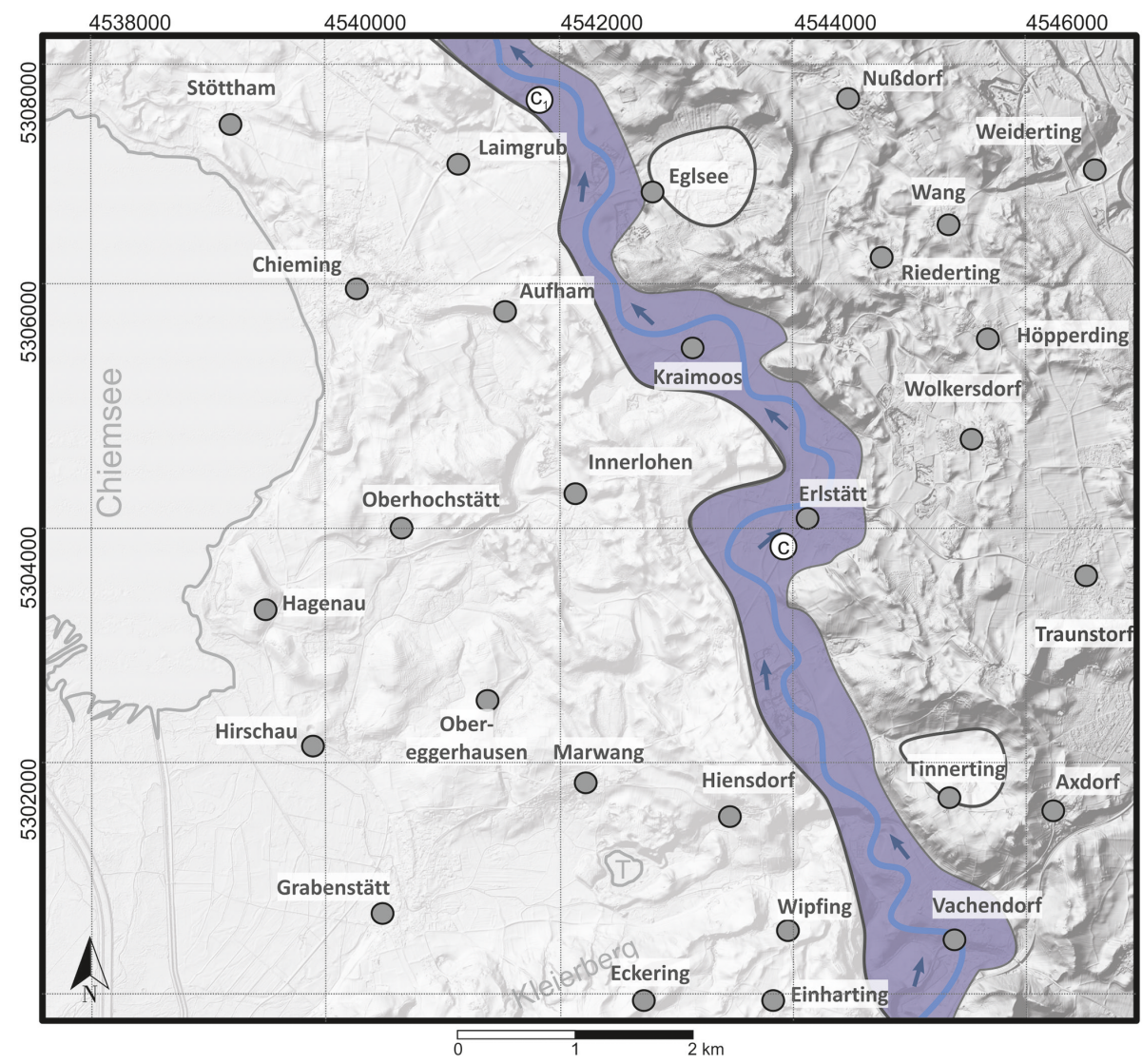

Abb. 18. Phase 4. Die Bad Adelholzen-Erlstätter Rinne (c in Abb. 5). Alle zentrifugal entwässernden Rinnen sind trockengefallen. Von Bad Adelholzen über Vachendorf und Erlstätt zieht in peripherer Richtung ein bei Erlstätt bis zu $1 \mathrm{~km}$ breites Kiesband westlich von Eglsee nach NW (c1 in Abb. 5). Geobasisdaten (C) Bayerische Vermessungsverwaltung.

des Eisrandsees. Die von Ganss (1977) kartierten Abschlämmmassen zwischen dem heutigen Tüttensee-Auslauf und dem Beginn der Obereggerhausener Rinne können damit als Ablagerung des Marwanger Eisrandsees interpretiert werden. Die Untere Tüttensee-Terrasse unterscheidet sich in Teilen sedimentologisch deutlich von den Oberen, denn die östlichen Bereiche der unteren Terrasse mit rundlichem Querschnitt, sowie der Rücken von Lug, bestehen aus Diamikten. Diese Teile stellen damit wohl eine Oser-artig ausgeprägte Grundmoräne bzw. subglazial gebildeten Till dar. Bei den westlichen, Kames-artigen Bereichen mit ebener Oberfläche finden sich dagegen über den Diamikten, eingeleitet von einem Aufarbeitungshorizont, überwiegend undeutlich geschichtete Kiese. Wir deuten diese Kiese insgesamt als glazifluviale Ablagerungen eines zwischen aktivem Gletscherrand und Toteis mäandrierenden Flusssystems. Das Flusssystem ist in erster Linie vom Eis in der Grabenstätter Bucht sowie aus der Wipfinger Rinne gespeist worden. Dazu hat auch noch Schmelzwasser aus der Bergener Bucht für Sedimentzufuhr in die Grabenstätter Bucht gesorgt.

\subsubsection{Die Eiszerfallslandschaft bei Oberhochstätt und die Grabenstätter Bucht}

Der Eiszerfall im Bereich der Grabenstätter Bucht ( $j$ in Abb. 5) und weiter nördlich setzte sich fort (Abb. 23-25). Nördlich von Obereggerhausen ist heute eine moorige Senke anzutreffen, in der sich die Tiefenbach-Rinne (g in Abb. 5) nur noch schwer erkennen lässt. Hier lag vermutlich Toteis (Abb. 24). In einer Kiesentnahmestelle bei Hagenau fanden wir schräggeschichtete, matrixfreie Kiese. Die Kiese sind überlagert von geringmächtigen horizontal gelagerten Kiesen. Der Aufschluss bietet somit einen Einblick in Foresetsowie Topset Sedimente eines kleinen Eisranddeltas. Nordnordöstlich von Hagenau trafen wir in einem Drainagegraben (in ca. $70 \mathrm{~cm}$ Tiefe unter humosem bis torfigem Boden) hellgraue Tone mit akzessorischen Sand- und Kieskomponenten an. Vermutlich zeigen diese Tone zumindest episodische Überflutungen an dieser Stelle an. Bei Oberhochstätt finden sich zudem noch ausgedehnte moorige Senken, die als Überreste von Toteislöchern bzw. Eisrandseen zu sehen sind. Es bietet sich hier so das Bild einer durch Eiszerfall geprägten Seen- und Auenlandschaft, die von Ganss (1977:186) so treffend als ,amphibische Landschaft" bezeichnet wurde. 


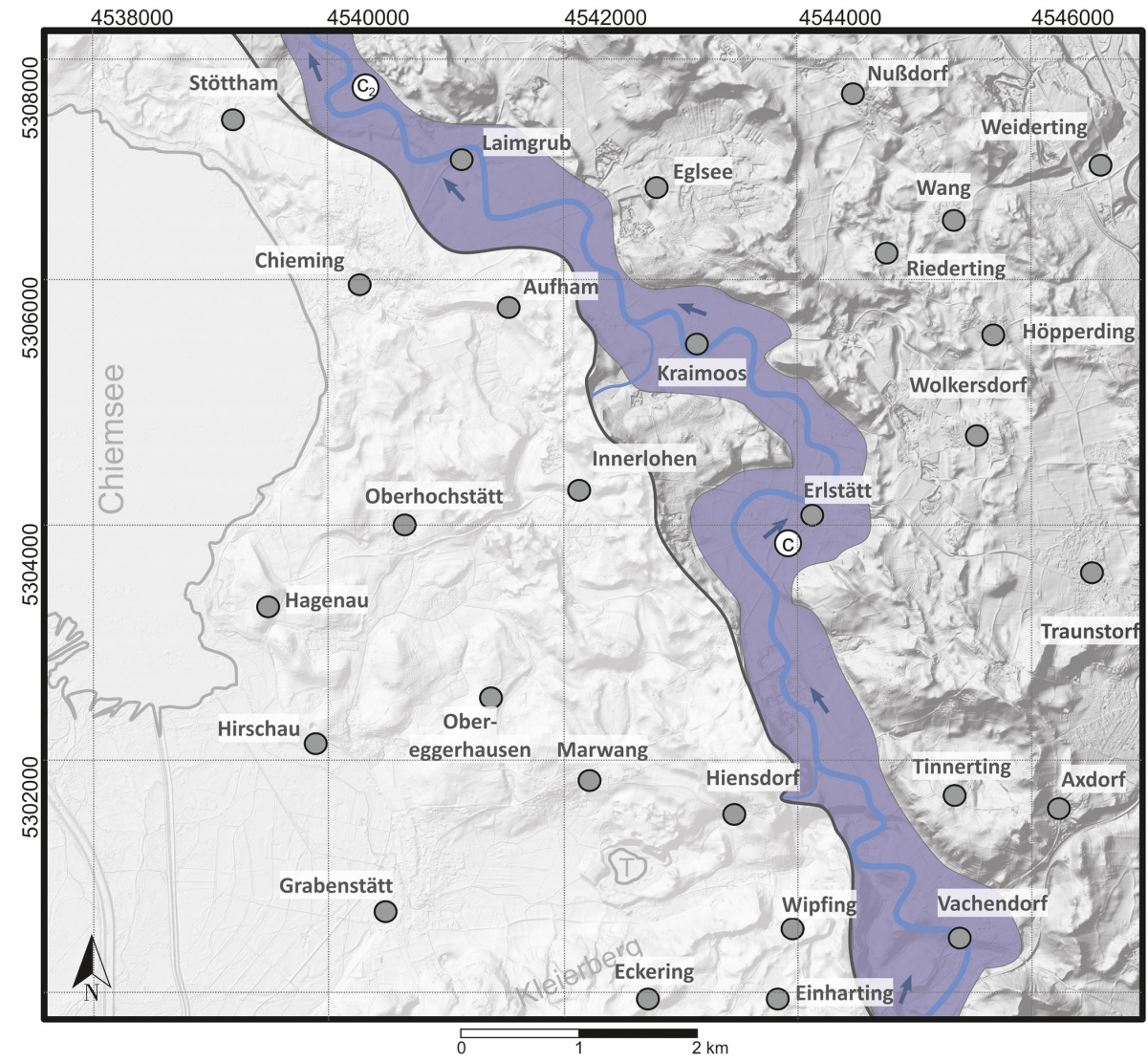

Abb. 19. Phase 5. Ein Schritt zum Wechsel in die zentripetale Entwässerungsrichtung (c2 in Abb. 5). Von Bad Adelholzen bis Eglsee bleibt der Abfluss erst einmal gleich, nimmt aber dann den Weg über Laimgrub, wo das Schmelzwasser viel weiter westlich und auf niedrigerem Niveau nach NW fließt. Bei Hiensdorf zeichnet sich die Entwicklung der Hiensdorfer Rinne ab (d in Abb. 5), deren Schmelzwasser in diesem Stadium noch nach Osten fließt. Geobasisdaten (C) Bayerische Vermessungsverwaltung.

Mit dem Zerfall des Beckeneises in der Hirschauer Bucht öffnete sich von Oberhochstätt nach Hirschau mit der Hirschauer Rinne (Abb. 24; $i$ in Abb. 5) ein neuer Abflussweg nach Süden. Damit fiel der bisherige Abfluss, die Tiefenbach-Rinne zwischen Oberhochstätt und Chiemsee, trocken. Im gerade noch existierenden Marwanger Eisrandstausee dauerte die Bildung der Unteren Tüttensee-Terrasse mit ihrem Delta an.

Das bis in $70 \mathrm{~m}$ Tiefe reichende Beckeneis der Grabenstätter Bucht ( $\mathrm{j}$ in Abb. 5) schmolz randlich so weit ab, dass der Marwanger Eisrandstausee nicht mehr über die Obereggerhausener und Tiefenbach-Rinne abfließen musste (Abb. 25). Das Schmelzwasser konnte nun seinen Weg direkt in den Chiemsee bei Hirschau nehmen. Die Schmelzwässer aus dem Tiroler Achental und der Bergener Bucht transportierten entlang des östlichen Gletscherrandes Kiese in die Grabenstätter Bucht und ließen so die Terrassenkante von Grabenstätt entstehen. Die Entstehung des Tüttensees und seiner Umrahmung war damit beendet und die Seesedimentation sowie die Torfbildung in der Tüttensee-Hohlform konnten beginnen. Die Datierung dieser Torfe und der Seekreide bis in $4 \mathrm{~m}$ Tiefe, und damit des Abschlusses der Entstehung des Tüttensee-Komplexes, ergab ein Mindestalter von bis zu 12750 Jahre BP (Bayerisches Landesamt für Umwelt, 2019).

\subsection{Das Toteisgebiet von Chieming}

Nordöstlich von Chieming entwickelte sich schon seit der aktiven Phase der Hiensdorfer Rinne (d in Abb. 5; Abb. 20) ein Eiszerfallsgebiet. Als die Hiensdorfer Rinne ihre volle Tätigkeit entwickelt hatte, dürfte sie westlich von Aufham auf diesen zerfallenden Gletscherrand getroffen sein. Zuerst schüttete sie noch zwischen dem östlichen Gletscherrand und dem Sporn von Aufham am Gletscherrand vorbei (Abb. 20). Etwas später schüttete sie, zusammen mit den direkt aus dem Gletscher kommenden Schmelzwässern, die ganz flach von Chieming nach Laimgrub fallende Ebene auf. Dabei kam sie anfänglich noch mit den verbleibenden Schüttungen der Bad Adelholzen-Erlstätter Rinne in Kontakt (Abb. 21). Später zerfiel der Gletscherrand in einzelne Toteisblöcke, was zum Beispiel das Toteisloch Pfeffersee $(R=4540$ 147, $H=5305$ 758; Ganss, 1977:187) oder die Wolfsgrube $(\mathrm{R}=4540339, \mathrm{H}=5306374)$ im Ortsbe- 


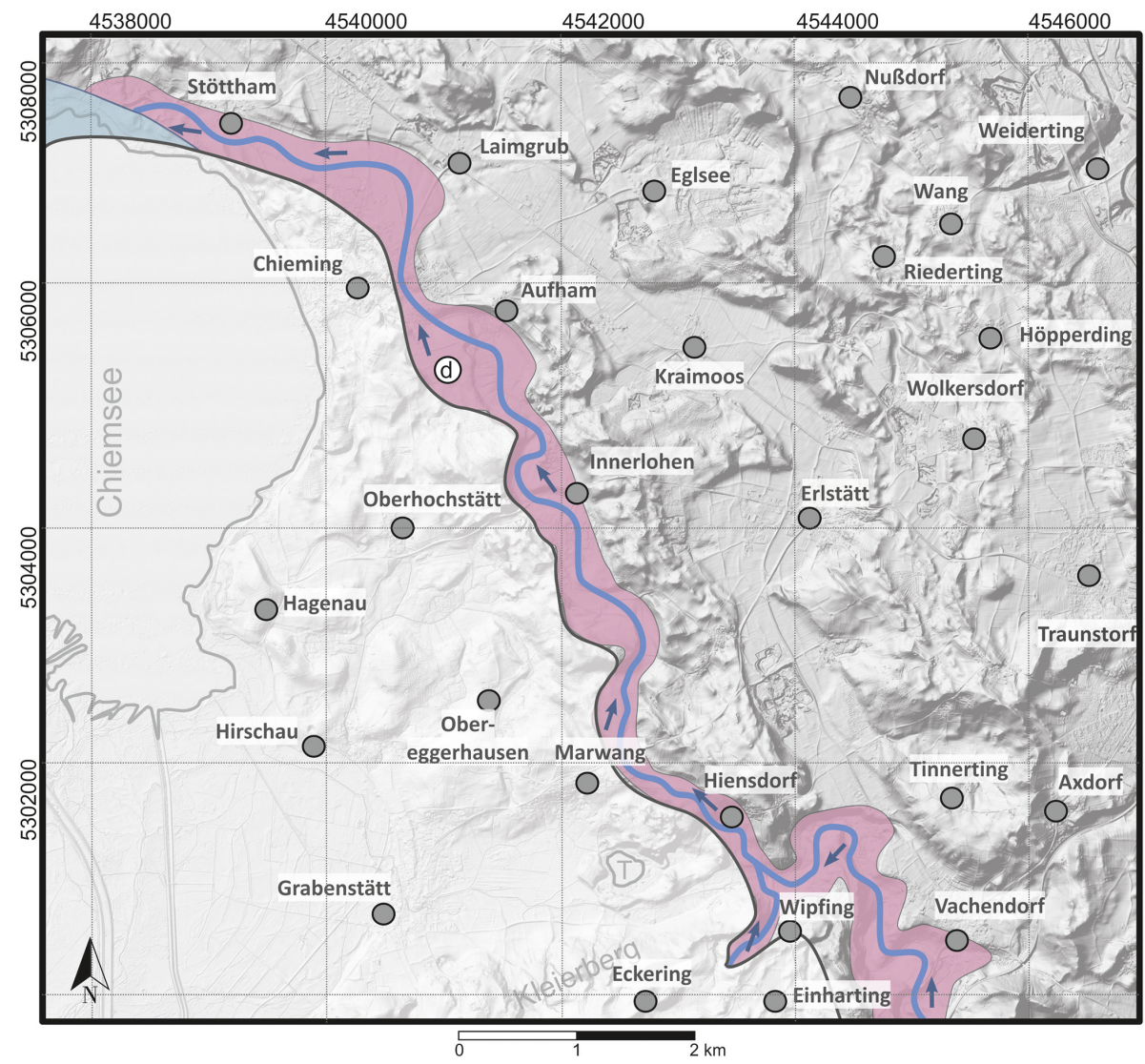

Abb. 20. Phase 6. Entstehung der Hiensdorfer Rinne (d in Abb. 5). Der Eisrand verlegt sich immer weiter Richtung Chiemsee-Becken. Während dieser Entwicklung kann der Großteil des vorher in der Bad Adelholzen-Erlstätter Rinne fließenden Wassers bei Hiensdorf einen Abfluss westlich des Moränenzugs von Aufham-Hiensdorf finden. Das Schmelzwasser mündet bei Stöttham in den nun dort eisfrei werdenden Chiemsee. Bei Wipfing entsteht ein Gletschertor, aus dem Schmelzwasser vom östlichen Kleierberg in die noch eisgefüllte Grabenstätter Bucht und über das Eis in die Hiensdorfer Rinne abfließt. Geobasisdaten () Bayerische Vermessungsverwaltung.

reich von Chieming belegt. Das direkt aus dem Gletscher abfließende Schmelzwasser mischte sich im Labyrinth dieser Toteisblöcke mit dem Wasser der Hiensdorfer Rinne und etwas später mit dem Wasser der Marwanger Rinne (e in Abb. 5; Abb. 21), sodass sich zwischen den Toteisblöcken verstärkt Kies-, Sand- und Tonablagerungen bilden konnten. Die Kaltenbach-Rinne ( $f$ in Abb. 5) schüttete bereits auf einem so tiefen Niveau, dass ihre Sedimente über das Pfeffersee-Toteis in Richtung Chiemsee transportiert wurden (Abb. 22).

Insgesamt ergibt sich das Bild, dass die Entstehung und Ausformung des Chieminger Toteisgebietes stark von der Entwicklung der Abflussrinnen aus dem Tüttensee-Komplex (Hiensdorfer, Marwanger und Kaltenbach-Rinne) beeinflusst worden ist. Durch die Sedimentation von Gesteinsmaterial unterschiedlichster Korngrößen entstand in dem Toteisgebiet ein kleinräumiges Nebeneinander von Tonen, Sanden, Kiesen und Blöcken (Findlingen) bis zu mehreren Kubikmetern Volumen (vgl. Ganss, 1977:183ff.).

Die Sediment-führenden Schmelzwässer aus der Kaltenbach-Rinne wurden unmittelbar südlich von Aufham nach Westen abgelenkt, so dass hier ein Prallhang entstand. Die Sedimentfracht gelangte so in den nun schon niedriger spiegelnden Chiemsee mit den Toteisblöcken am Südrand Chiemings. Dieser Prallhang zeigt eine ganze Reihe von Terrassen, die das Einschneiden der Kaltenbach-Rinne zu dokumentieren scheinen. $\mathrm{Zu}$ dieser Zeit muss im Bereich des Pfeffersees ein Toteiskörper gelegen sein, der erst abschmolz, als die Kaltenbach-Rinne kein Schmelzwasser mehr über den Marwanger Eisrandstausee (siehe unter Abschnitt 5.2.2) bekam. Die Kaltenbach-Rinne wandelte sich ab diesem Zeitpunkt zu einem Trockental, das bis heute nur noch von einem wenig Wasser führenden Bach durchflossen wird. Daher kam durch die Kaltenbach-Rinne kaum mehr Sediment nach Chieming.

Offenbar ist fast das gesamte Ortsgebiet von Toteis geformt worden. Während die Kiesebene von Laimgrub ganz flach und gleichmäßig gegen Chieming ansteigt, ist der zum Chiemsee abfallende Hang im Ortsgebiet Chiemings von einer Vielzahl von Senken und Erhebungen gekennzeichnet. Der Übergang von der Kiesebene in den Hang folgt keiner „glatten“ Linie, sondern erscheint unregelmäßig (Abb. 3). 


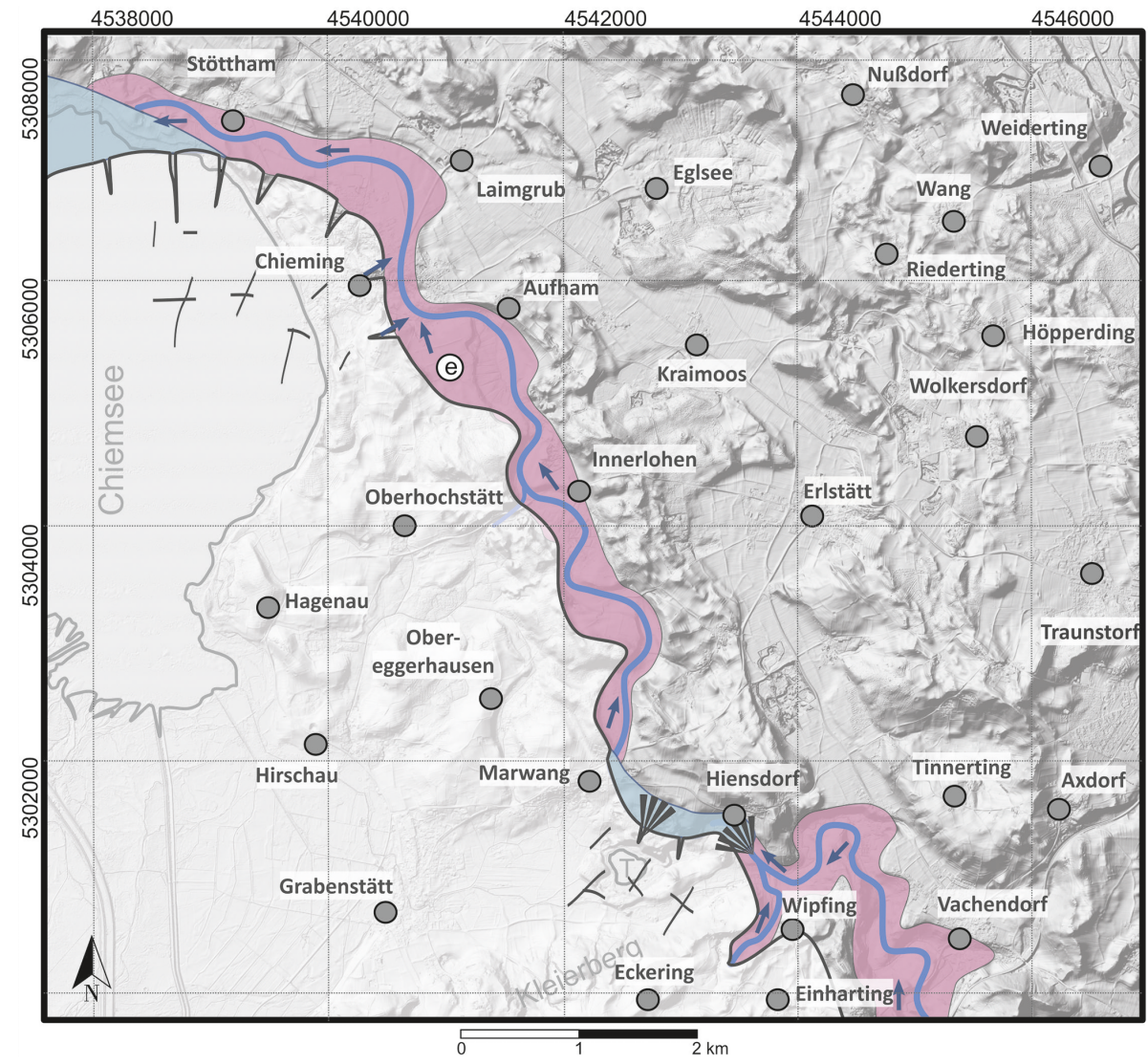

Abb. 21. Phase 7. Zwischen Hiensdorf und Marwang entwickelt sich der über die Marwanger Rinne (e in Abb. 5) abfließende Marwanger Eisrandstausee. Aus dem Gletschereis und der südöstlichen Rinne kommende Bäche schütten in ihm die Kames-Deltas des Hügels von Mühlbach (Mü in Abb. 8) und der Oberen Tüttensee-Terrasse (OTT I in Abb. 8) auf. Bei Chieming beginnt sich ein größeres Eiszerfallsgebiet zu entwickeln. Geobasisdaten (C) Bayerische Vermessungsverwaltung.

Mit dem Toteis hängt wohl auch eine dünenartig wirkende Kiesablagerung am Nordrand von Chieming $(\mathrm{R}=4539619$, $\mathrm{H}=5306528$ ) nahe des Chiemseeufers zusammen, die man als eine Eisspaltenfüllung zwischen zwei Eisblöcken interpretieren kann. Dafür spricht der von Ganss (1977:184) erwähnte (sic!) „Moränenwall“? nördlich von Chieming, aus gut geschichtetem Feinkies mit Sandlagen. Dort wurden auch zwei erratische Brekzienblöcke freigelegt.

Während der Entstehungszeit des Chieminger Eiszerfallsgebietes lenkte also das als Barriere wirkende ChiemseeGletschereis an seinem Ostrand zwischen Marwang-West, Oberhochstätt und Chieming das Schmelzwasser in der ungefähr gleichbleibenden Rinne von Hiensdorfer, Marwanger und Kaltenbach-Rinne nach Norden Richtung Chieming. Durch diese Eisblockade entwickelte sich auch der Marwanger Eisrandsee (Abb. 21-24), der die Entstehung des Tüttensee-Komplexes möglich machte.

\subsection{Zur zeitlichen Stellung des Abschmelzgeschehens}

Wie Ivy-Ochs et al. (2006; darin auch die Literaturbelege) zusammenfassen, begannen die großen, bis ins Alpenvorland reichenden Gletscher im Zeitraum 21 000-19000 BP zusammenzubrechen. Das nächste jüngere, ausreichend datierte Ereignis war das Gschnitz-Stadial. Das Alter der GschnitzMoräne (Tirol, nahe Trins bei Steinach am Brenner) wurde mit ${ }^{10}$ Be-Expositionsdatierung auf $15400 \pm 1400$ Jahren BP angegeben (Ivy-Ochs et al., 2006). Zu dieser Zeit war also das Inn-Tal schon weitgehend eisfrei. Für den Bereich des österreichischen Traun-Tals belegen ${ }^{14} \mathrm{C}$-Analysen in Mooren, dass auch dort die Täler seit mindestens $15400 \pm 470$ Jahren BP eisfrei waren (Draxler, 1977; Van Husen, 1977). Demnach wird für die dargelegten Vorgänge am östlichen Rand des Inn-Chiemsee Gletschers, die zur Entstehung des Tüttensee-Komplexes führten, ein Zeitraum von wenigen Jahrhunderten um oder knapp nach 19000 BP anzunehmen sein.

\subsection{Bezüge zum angeblichen Chiemgau Impakt}

Der Tüttensee steht seit einigen Jahren im Zentrum einer umstrittenen These, wonach der See der Einschlagkrater eines Kometen, Kometenbruchstücks oder Meteoriten ist (z.B. Ernstson, 2010; Ernstson et al., 2010). Diese These wurde 


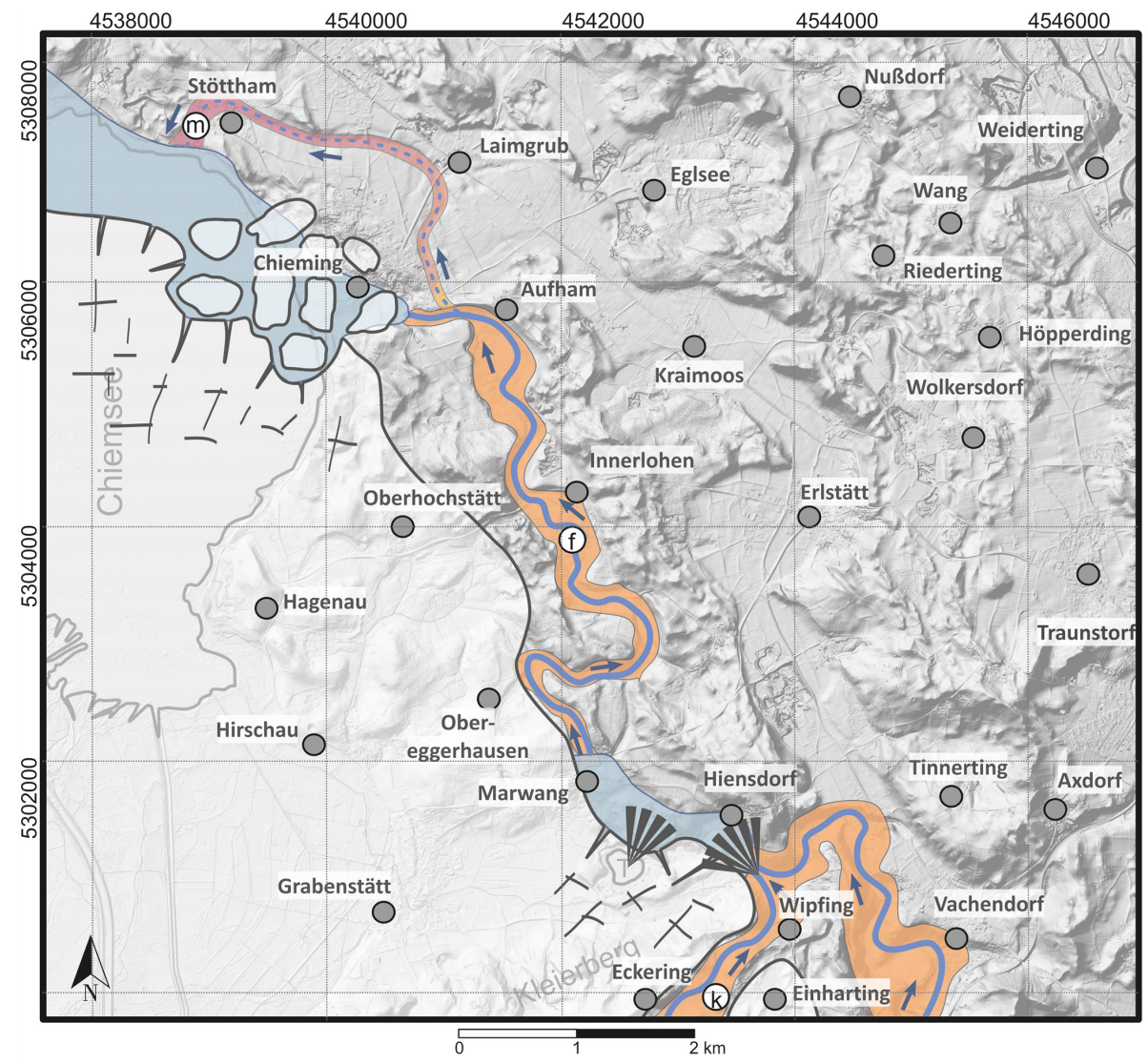

Abb. 22. Phase 8. Die Entstehung der Oberen Tüttensee-Terrasse OTT II und der Kaltenbach-Rinne (vgl. II und f in Abb. 5), sowie des Eiszerfallgebiets von Chieming. Die Lohbach-Rinne (hier gestrichelt; $m$ in Abb. 5) ist als Endstadium der Marwanger Rinne zu interpretieren. Geobasisdaten () Bayerische Vermessungsverwaltung.

bereits mehrfach kritisch diskutiert (z.B. Doppler und Geiss, 2005; Wünnemann et al., 2007; Darga, 2009b), wobei die Autoren die von den Vertretern der Impakt-These vorgebrachten Belege als nicht belastbar einstufen.

Der „Chiemgau Impakt“ wird von einer Gruppe aus Laienforschern und Wissenschaftlern postuliert, die sich selbst Chiemgau Impact Research Team (CIRT) nennt und in den letzten Jahren eine Reihe von Schriften zu diesem Thema vorgelegt hat. Die Deutung des Sees als Krater beruht nach Ernstson et al. (2010) vor allem auf der wallartigen Umrahmung des Sees, dem Vorkommen von Diamikten in der Umgebung und dem Fund von deformierten Geröllen sowie mikroskopischen Deformationsstrukturen (z.B. planare Lamellen in Quarz). Des Weiteren wurden Funde von verglasten Geröllen, tuffartigem Material, exotischen Eisensiliziden und kohlenstoffhaltigem Material, sowie der Befund einer Schwereanomalie im südlichen Bereich des Sees angeführt.

Der Großteil dieser Indizien wurde in den letzten Jahren widerlegt. So wurde beispielsweise das als impaktdiagnostisch publizierte, exotische Material, weitgehend als anthropogen identifiziert (Bayerisches Landesamt für Umwelt, 2012:82ff.; Huber et al., 2017; Smith et al., 2019).
Demnach stellen die Eisensilizide Fabrikationsrückstände der Düngemittelindustrie dar, das kohlenstoffhaltige Material verweist auf Rückstände von Koks bzw. Kunststoffen. Das tuffartige Material wurde als Schlacke der alten Eisenhütten in der Region identifiziert und verglaste Silikatgerölle entstanden und entstehen noch heute in Kalkbrennöfen sofern mit dem kalkigen Brenngut auch Silikate in den Brennraum eingebracht werden. Daneben stellen die makroskopischen Deformationen an Steingeröllen bereits alpin deformiertes Geschiebe dar. Diese Geschiebe wurden von Gletschern und Fließgewässern an die Fundorte verfrachtet. Dort konnte die natürliche Verwitterung selektiv einwirken und löste z.B. den Kluftkalzit aus Radiolaritgeröllen, so dass derartige Gerölle in verwittertem Zustand zerbrochen aussehen (vgl. Abb. 1 in Darga, 2009b; Doppler und Geiss, 2005). Zudem wurden die mikroskopischen Deformationsstrukturen an Quarz von Wünnemann et al. (2007) angezweifelt.

Wir selbst konnten bei unseren Geländebegehungen und Beprobungen keinerlei Material finden, das sich nicht zwanglos durch die von uns beschriebene glazifluvial Genese erklären ließe. In den Sedimentproben aus dem Anstehenden der Lokationen rund um den Tüttensee wurden weder 


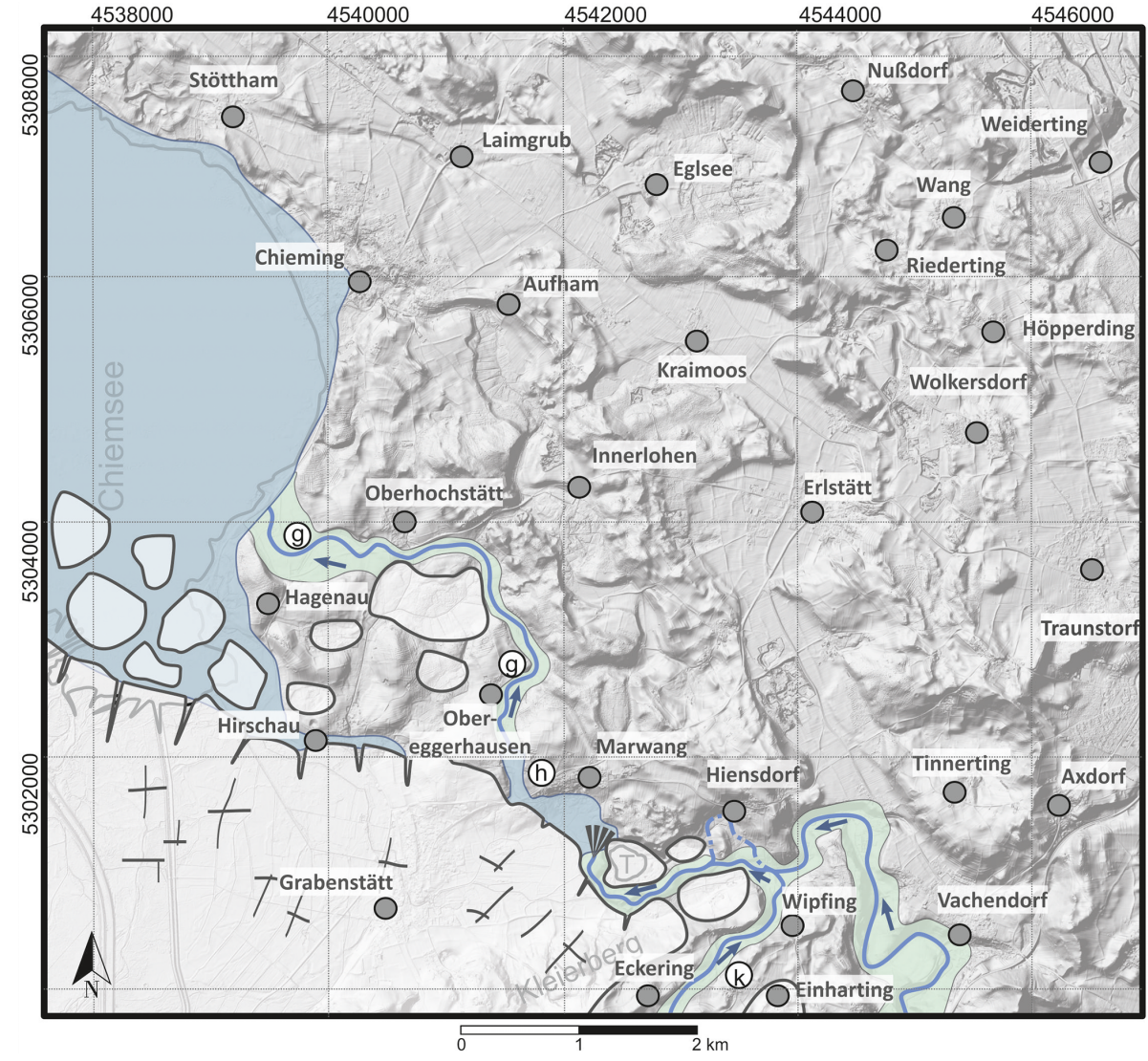

Abb. 23. Phase 9. Entstehung der Unteren Tüttensee-Terrasse (UTT), der Obereggerhausener und der Tiefenbach-Rinne (vgl. III, h und g in Abb. 5). Der Eiszerfall in der Grabenstätter Bucht führt zur Bildung von Oser- und Kames Ablagerungen, die im Bereich des Marwanger Eisrandstausees ein Delta bilden. Die Entwässerung des Stausees erfolgt über die Obereggerhausener und Tiefenbach-Rinne an Oberhochstätt vorbei bis in den Chiemsee. Geobasisdaten (C) Bayerische Vermessungsverwaltung.

Schlacken, noch Eisensilizide, noch angeschmolzene Gerölle festgestellt. Nur an einer Stelle (Lokation TS25) wurden Schlacken vorgefunden, und zwar zusammen mit offensichtlich altem Bauschutt und Hausmüll.

Dass die Deutung der Morphologie der den Tüttensee umgebenden Hügel als Kraterwall nur schwer nachzuvollziehen ist, wurde bereits angeführt (Darga, 2009b; Doppler und Geiss, 2005). Die Umrahmung des Sees ist keineswegs kraterartig geformt, sondern ist mehrfach durchbrochen. Sie ist vielmehr in zwei klar voneinander abgrenzbare Terrassenkörper geteilt. Der „Kraterwall“ hat im Bereich der Unteren Tüttensee-Terrasse besonders im Südwesten und Westen eine auffallend ebene Oberfläche und auch die Oberen Tüttensee-Terrassen besitzen eine fast plane Oberfläche. Dieser Formenschatz ist mit keiner bekannten Impaktbildung in Einklang zu bringen. Hier sei noch einmal darauf hingewiesen, dass das Liegende des Tüttensee-Komplexes aus glazialen Diamikten besteht. Vor allem der westliche Teil des „Walls" besteht dagegen aus geschichteten, feinkornarmen Kiesen. Die Kiese im Nordwesten des „Walls“ zeigen sogar eine Deltaschichtung mit einem Einfallen nach Norden. Die- se Sedimente sind also völlig anders geartet als die darunterliegenden unsortierten, ungeschichteten, feinkornreichen Diamikte und können daher nicht als Auswurfmasse derselbigen interpretiert werden.

In den südöstlichen und östlichen Teilen der TüttenseeUmrahmung ist eine Änderung der Lithologie hin zu Diamikten zu beobachten. Trotzdem ist in einer GeoradarDarstellung von Tengler (2015) und Poßekel und Ernstson (2019) eine Schichtung zu erkennen, die die Autoren als umgelagerte Ejektamassen interpretieren. Diese Schichtung ist nach unseren Geländebefunden jedoch die Sedimentfüllung eines Oses (Füllung einer Spalte oder eines Tunnels im Eis). Durchaus vergleichbare Sedimentstrukturen und Geländeformen wurden auch aus dem Würm-Endmoränengebiet des Salzach-Gletschers, östlich der Salzach, beschrieben (Götz et al., 2018:260, deren Abb. 4c).

Grundsätzlich ist zwar eine gewisse ballistische Sortierung von Impaktiten möglich, keinesfalls aber so ausgeprägt, wie in den von uns beobachteten fragilen Texturen der Anreicherungen von reinen, matrixfreien Grobkiesen am Tüttensee. Dies und die an verschiedenen Stellen nachgewiese- 


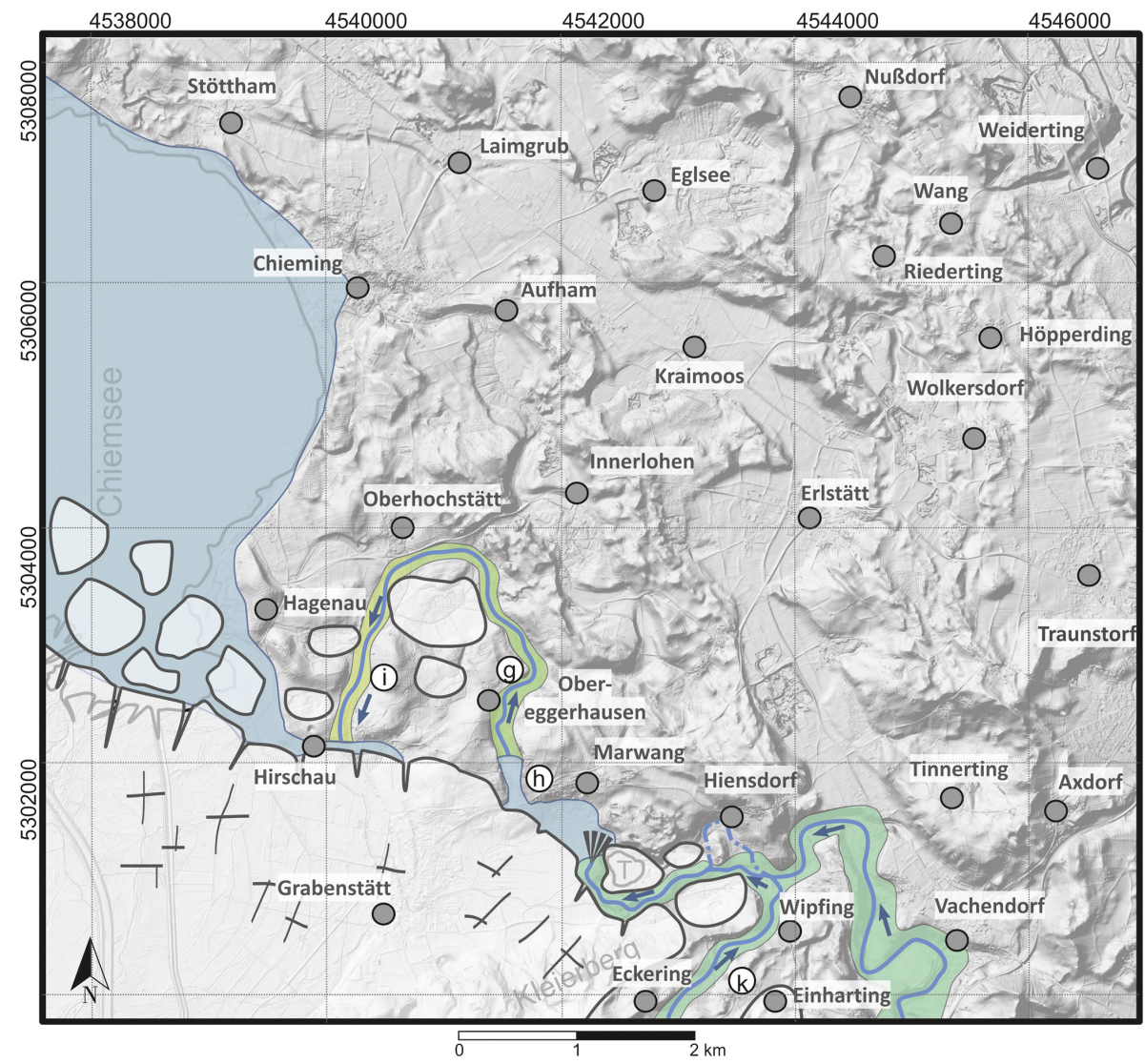

Abb. 24. Phase 10. Entstehung der Hirschauer Rinne (i in Abb. 5). Das zerfallende Eis in der Hirschauer Bucht macht den Weg frei für die Hirschauer Rinne. Die Entwässerung des Marwanger Eisrandstausees erfolgt nun im großen Bogen zuerst nach Norden, nach Oberhochstätt umbiegend, und dann nach Süden in die Hirschauer Bucht. Im gerade noch existierenden Marwanger Eisrandstausee dauert die Bildung der Unteren Tüttensee-Terrasse mit ihrem Delta noch an. Geobasisdaten (C) Bayerische Vermessungsverwaltung.

nen Deltaschichtungen belegen dagegen eine Entstehung der Tüttensee-Terrassen durch fließendes Wasser. Eine Impaktgenese kann für diese Sedimente somit ausgeschlossen werden.

Auch eine Umformung des Tüttensee-Komplexes und der weiteren Umgebung durch einen Tsunami wurde in den letzten Jahren postuliert (z.B. Ernstson, 2016; Liritzis et al., 2010). Dazu wurde eine Vertiefung im Chiemsee-Boden als Beleg für den auslösenden Einschlag gedeutet. Die wenig präzisen Angaben der Autoren zur Lage dieser Vertiefung lokalisieren sie in etwa $30 \mathrm{~m}$ Wassertiefe, in der Nähe der Untiefe "Der Kaiser" bei Chieming. Für die Sedimente einer Baugrube in Stöttham (Liritzis et al., 2010) wurde vor einigen Jahren bereits ein ursächlicher Zusammenhang mit diesem Chiemsee-Tsunami hergestellt. Diese These wurde von Völkel et al. (2012) überzeugend widerlegt, der diese Sedimente als holozäne, kolluviale Rinnenfüllung interpretiert.

Dies deckt sich mit unseren Befunden, denn an den fragilen Tüttensee-Terrassen sind keinerlei Spuren eines solchen Ereignisses feststellbar. Und nachdem Ernstson (2016) den angenommenen Tsunami auch in den mächtigen schräggeschichteten Kiesen in den Kiesgruben bei Eglsee (Abb. 6) zu erkennen meint, müssten auch die Oberen TüttenseeTerrassen vom Tsunami überflutet worden sein. Zumindest müssten, wenn die postulierte Flutwelle bis Eglsee reichte, angesichts der Massen der dort angeblich vom Tsunami abgelagerten Kiesmassen auch die Toteislöcher im Ortsbereich von Chieming zugeschüttet worden sein. Ein entsprechender Befund liegt jedoch nicht vor. Vielmehr ist im Schwarzelmoos, im nördlichen Chieminger Ortsbereich, das bis 6 Meter mächtige Übergangsmoor ohne Kiesbedeckung. Der ebenfalls unter Abschnitt 4.1.3 beschriebene Kies- und Sandrücken wenige Meter westlich des Schwarzelmooses kann somit auch nicht von einem Tsunami erzeugt worden sein. Seine von Ganss (1977:184) beschriebene Sedimentologie - ,... gutgeschichtetem Feinkies mit Sandlagen ...“ - spricht in Verbindung mit der engen Nachbarschaft zur Schwarzelmoos-Hohlform ebenfalls gegen eine TsunamiAblagerung.

Kreuz- und Schrägschichtung finden sich zwar auch in Tsunami-Sedimenten, allerdings nur sehr kleinskalig, im Gegensatz zu den meterweiten Schwüngen der Eglseer Schichtung. Tsunami-Sedimente sind zudem maximal einige Dezimeter mächtig (Peters und Jaffe, 2010). Auch dies steht 


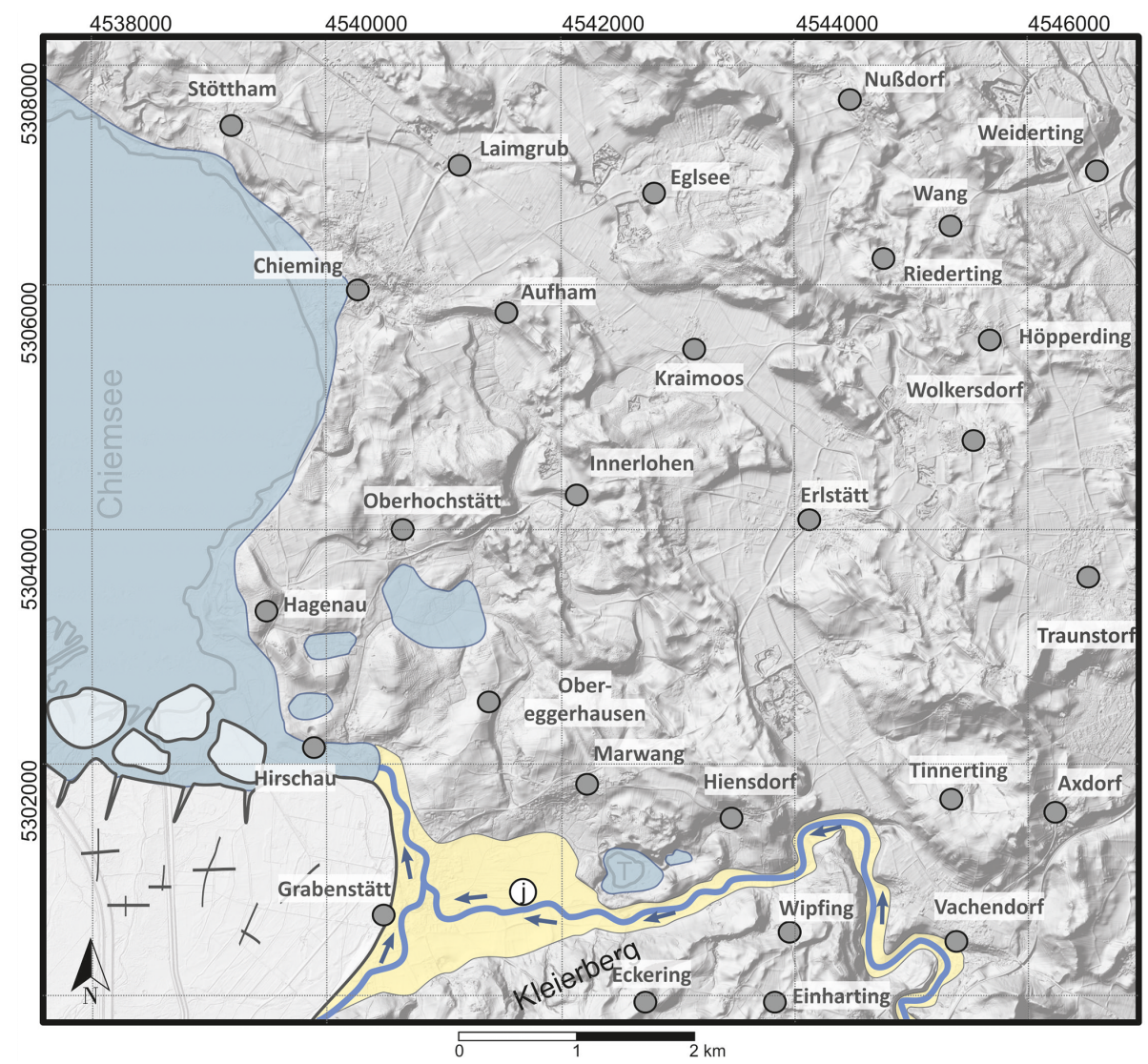

Abb. 25. Phase 11. Der letzte Schritt zur Entstehung der Grabenstätter Bucht in ihrer heutigen Form (j in Abb. 5). Alle ab Phase 4 im Bereich des Tüttensees aktiven Schmelzwasserrinnen wurden vom Grabenstätter Mühlbach abgelöst. Der Tüttensee-Komplex ist seit Eintritt dieser Phase keinen größeren Veränderungen mehr ausgesetzt gewesen. Die aus dem Süden zwischen Kleierberg und dem Beckeneis am Westende der Grabenstätter Bucht geschütteten Kiese bilden die heutige Westbegrenzung der Grabenstätter Bucht. Geobasisdaten $\odot$ Bayerische Vermessungsverwaltung.

im Widerspruch zu den mehrere Metern mächtigen Erlstätter und Eglseer Kiesen. Aufgrund der Lage der Eglseer Kiesgrube innerhalb der prägnanten Erlstätter Rinne, ist sie eindeutig als altes Flussbett zu charakterisieren.

In der Summe der Befunde ist es aus unserer Sicht gänzlich unverständlich, warum diese Formen als TsunamiSedimente angesprochen wurden. Der sedimentologische und morphologische Befund lässt sich ganz ohne Tsunami erklären.

Unsere durch Geländeuntersuchungen und Kartierungen gewonnenen lithologischen Befunde sowie die Lagerungsverhältnisse der Lithologien belegen eine glaziofluviale Entstehung des Tüttensee-Komplexes. Die von Ernstson (2010) auf Grund geophysikalischer Messungen erkannte und als Impaktkrater interpretierte Hohlform unter dem Tüttensee gehört zu einem viel größeren Rinnensystem in der MolasseOberfläche (Abb. 4). Diese Hohlform ist daher deutlich älter als der propagierte Impakt. Mit geophysikalischen Methoden gewonnene Ergebnisse (Messungen) müssen sich stets an den geologischen Realitäten messen lassen (siehe z.B. Koeberl und Martinez-Ruiz, 2003).
Die Entstehung der Tüttensee-Senke durch einen Impakt ist damit rein hypothetisch. Kroemer (2009) hat das Alter der Tüttensee-Senke ${ }^{14} \mathrm{C}$-datiert und gibt das Mindestalter der Hohlform mit CalBP 12750 bis 12390 Jahren an. Der Tüttensee existierte also schon mindestens ca. 9000 Jahre vor dem vermeintlichen Impakt, der nach Ernstson et al. (2010) höchstwahrscheinlich zwischen 1300 und 300 BC stattfand. Der Tüttensee-Impakt hätte somit einen Volltreffer in ein möglicherweise bereits vollkommen verlandetes Toteisloch gelandet, was unsere Befunde jedoch eindeutig ausschließen.

Am auffälligsten am Tüttensee-Komplex sind die Höhen der Tüttensee-Terrassen. Alle drei korrespondieren mit einer, der in dieser Arbeit beschriebenen peripheren Abflussrinnen (Tabelle 1). Die Schmelzwässer, die die oberste Terrasse (OTT I) aufschütteten, flossen über die Marwanger Rinne ab. Die untere der beiden oberen Terrassen (OTT II) entließ ihre Schmelzwässer etwas später über die Kaltenbach-Rinne. Und die Untere Tüttensee-Terrasse (UTT) entwässerte über die Obereggerhausener Rinne in die Tiefenbach-Rinne. Zwischen jeder dieser Terrassen und dem zugehörigen Abfluss befinden sich heute tiefer liegende Geländebereiche. Dass die 
drei Tüttensee-Terrassen in ihren Höhenlagen mit drei der peripheren Rinnen korrespondieren, ist nicht zufällig. Um das Schmelzwasser in diese Rinnen fließen lassen zu können, musste ein „Damm“ existiert haben, der den direkten Abfluss dieser Wässer in die Grabenstätter Bucht verhinderte. Hierfür kommt nur Gletschereis in Frage. Ein Impakt eines extraterrestrischen Körpers ist zur Erklärung der Geländestrukturen des Tüttensee-Komplexes als Teil des südöstlichen Chiemsee-Gebiets nicht notwendig. Die Sedimentologie spricht eindeutig gegen einen Impakt.

\section{Fazit}

Die in Abb. 1 umrissene Fläche wurde insbesondere durch die Nutzung des Digitalen Geländemodells geomorphologisch und im engeren Bereich um den Tüttensee sedimentologisch erfasst. Die Befunde belegen ein sukzessives Abschmelzen der Würm-zeitlichen Gletschermassen vom durch das Traun-Tal nachgezeichneten östlichen Gletscherrand Richtung Westen bis an das heutige Chiemsee-Ufer. Die dabei entstandenen zentrifugalen, peripheren und zuletzt zentripetalen Schmelzwasserrinnen sind hierfür die offensichtlichsten Belege. Der ungefähr von den Verbindungslinien zwischen Grabenstätt - Stöttham - Eglsee - Vachendorf umgrenzte Geländebereich war Schauplatz einer vergleichsweise kleinteiligen Abschmelzgeschichte. Dabei ließ das Beckeneis des östlichen Chiemsee-Gletschers zuerst das Toteisgebiet von Chieming entstehen. Nachfolgend bildete sich das Toteisgebiet des Tüttensee-Komplexes, mit seinen drei heute noch belegbaren Abflussniveaus (Tabelle 1). Die Sedimentologie der Tüttensee-Umrahmung belegt eine Ablagerung als Os, als Kames und insbesondere mit seinen KamesdeltaSedimenten eine Ablagerung im Marwanger Eisrandstausee.

Datenverfügbarkeit. Alle Daten sind in PANGAEA archiviert und publiziert unter https://doi.org/10.1594/PANGAEA.907686 (Huber et al., 2019a) und https://doi.org/10.1594/PANGAEA.907672 (Huber et al., 2019b).

Autorenmitwirkung. RH und RD koordinierten gemeinschaftlich die Arbeiten. Alle Autoren waren an den Geländekampagnen, den Probennahmen und der sedimentologischen Kartierung beteiligt. Die sedimentologischen Analysen wurden von RH durchgeführt. RH und RD waren federführend bei der wissenschaftlichen Interpretation der Ergebnisse. Alle Autoren diskutierten die Ergebnisse und trugen zur Erstellung des finalen Manuskriptentwurfs bei.

Interessenkonflikt. Die Autoren erklären, dass kein Interessenkonflikt besteht.
Danksagung. Martin Nose (Bayerische Staatssammlung für Paläontologie und Geologie) und Matthias Brugger (Lehrstuhl für Ingenieurgeologie der Technischen Universität München) haben uns dankenswerter Weise bei der Besorgung von Literatur unterstützt. Wir danken Ulrike Munninger und Sylke Draschba für die kritische Durchsicht des Manuskripts, Ulrike Munninger auch für die Erstellung der Übersetzungen ins Englische. Wir danken unseren Reviewern Margot Böse und Dirk van Husen, deren kritische Kommentare und fachlicher Rat uns geholfen haben, das Manuskript zu verbessern.

Finanzierung. The article processing charges for this open-access publication were covered by the University of Bremen.

Begutachtung. This paper was edited by Christopher Lüthgens and reviewed by Margot Böse and Dirk van Husen.

\section{Literatur}

Bayberger, F.: Der Inngletscher von Kufstein bis Haag?: ein Beitrag zur Kenntniss der südbayerischen Hochebene, Petermanns Mitt, Ergänzungsband, 70, 1-67, 1882.

Bayerisches Landesamt für Umwelt: Nicht von dieser Welt. Bayerns Meteorite, 128 S., München, Deutschland, 2012.

Bayerisches Landesamt für Umwelt: Umweltatlas Bayern, Angewandte Geologie, Eiszerfallslandschaft des Tüttensees, GeotopNummer: 189R039, München, online aufrufbar: https://www. umweltatlas.bayern.de/mapapps/resources/reports/geotope/ generateBericht.pdf?additionallayerfieldvalue=189R039, letzter Zugriff: 23. Mai 2019.

Darga, R.: Auf den Spuren des Inn-Chiemsee-Gletschers - Übersicht, Wanderungen in die Erdgeschichte, 26, Pfeil Verlag, München, Deutschland, 175 S., 2009a.

Darga, R.: Der Chiemgau-Impakt - eine Spekulationsblase. Oder: Der Tüttensee ist KEIN Kometenkrater, in: Auf den Spuren des Inn-Chiemsee-Gletschers - Exkursionen, Wanderungen in die Erdgeschichte, Herausgeber: Darga, R. und Wierer J. F., 27, Pfeil Verlag, München, Deutschland, 174-185, online aufrufbar: https://de.scribd.com/document/26218026/DerChiemgau-Impakt-eine-Spekulationsblase-Oder-Der-Tuttenseeist-KEIN-Kometenkrater (letzter Zugriff: 18. März 2020), 2009b.

Doppler, G. und Geiss, E.: Der Tüttensee im Chiemgau - Toteiskessel statt Impaktkrater, 5; Bayerisches Landesamt für Umwelt, online aufrufbar: https://www.lfu.bayern.de/geologie/meteorite/ bayern/doc/tuettensee.pdf (letzter Zugriff: 10. Juni 2019), 2005.

Draxler, I.: Pollenanalytische Untersuchungen von Mooren zur spät- und postglazialen Vegetationsgeschichte im Einzugsgebiet der Traun, Jb. Geol. BA, 120, 131-163, 1977.

Ernstson, K.: Der Chiemgau-Impakt. Ein bayerisches Meteoritenkraterfeld, 1. Auflage, Chiemgau Impakt e.V., Traunstein, Deutschland, 80 S., 2010.

Ernstson, K.: Evidence of a meteorite impact-induced tsunami in Lake Chiemsee (Southeast Germany) strengthened, Lunar and Planetary Science Conference, 21.-25. März 2016, The Woodlands, Texas, USA, 47, 1263, 2016. 
Ernstson, K., Mayer, W., Neumair, A., Rappenglück, B., Rappenglück, M. A., Sudhaus, D., und Zeller, K.: The Chiemgau Crater Strewn Field: Evidence of a Holocene Large Impact Event in Southeast Bavaria, Germany, Journal of Siberian Federal University, Engineering und Technologies, 1/3, 72-103, 2010.

Ganss, O.: Geologische Karte von Bayern $1: 25000$, Erläuterungen zum Blatt Nr. 8140 Prien a. Chiemsee und zum Blatt Nr. 8141 Traunstein, Bayerisches Geologisches Landesamt, München, Deutschland, 344 S., 1977.

Gareis, J.: Die Toteisfluren des Bayerischen Alpenvorlandes als Zeugnis für die Art des spätwürmzeitlichen Eisschwundes, Würzburger Geographische Arbeiten, 46, 101 S., 1978.

German, R.: Sedimente und Formen der glazialen Serie, E\&G Quaternary Sci. J., 23/24, 5-15, https://doi.org/10.3285/eg.2324.1.01, 1973.

Götz, J., Salcher, B., Starnberger, R., and Krisai, R.: Geophysical, topographic and stratigraphic analyses of perialpine kettles and implications for postglacial mire formation, Geogr. Ann. A, 100, 254-271, https://doi.org/10.1080/04353676.2018.1446638, 2018.

Grimminger, H.: Verzeichnis der Seen in Bayern - mit einem Kartenteil, Teil 1 Text, Bayerisches Landesamt für Wasserwirtschaft, München, Deutschland, 427 S., 1987.

Henry, R. and Rudolph, N.: Genetisch-chronologische Studien im nördlichen Bereich des Inn-Chiemseegletschers, E\&G Quaternary Sci. J., 28, 83-91, https://doi.org/10.3285/eg.28.1.07, 1978.

Huber, R., Darga, R., and Lauterbach, H.: Pseudoimpactites in anthropocenically overprinted quaternary sediments, EGU General Assembly, 23.-28. April 2017, Wien, Austria, Geophys. Res. Abstr., 19, EGU2017-16545, 2017.

Huber, R., Darga, R., and Lauterbach, H.: Roundness of grains from sediments from the surroundings of Lake Tüttensee (Bavaria, Germany), PANGAEA, https://doi.org/10.1594/PANGAEA.907686, 2019a.

Huber, R., Darga, R., and Lauterbach, H.: Grain size distributions of sediments of the surroundings of Lake Tüttensee (Bavaria, Germany), PANGAEA, https://doi.org/10.1594/PANGAEA.907672, 2019b.

Ivy-Ochs, S., Kerschner, H., Kubik, P. W., und Schlüchter, C.: Glacier response in the European Alps to Heinrich Event 1 cooling: the Gschnitz stadial, J. Quaternary Sci., 21, 115-130, 2006.

Jerz, H.: Geologische Karte von Bayern 1:25000, Blatt Nr. 8041 Traunreut, Bayerisches Geologisches Landesamt, München, Deutschland, 1999.

Keller, B.: Lithofazies-Codes für die Klassifikation von Lockersedimenten, Mit. Sch. Ges., 132, 5-12, 1996.

Knauer, J.: Die Ablagerungen der älteren Würm-Eiszeit (Vorrückungsphase) im süddeutschen und norddeutschen Vereisungsgebiet, Abhandlungen der geologischen Landesuntersuchung am bayerischen Oberbergamt, München, Deutschland, 21, 65 S., 1935.

Koeberl, C. und Martinez-Ruiz, F.: The Stratigraphic Record of Impact Events: A Short Overview, in: Impact Markers in the Stratigraphic Record. Impact Studies, Herausgeber: Koeberl, C. and Martínez-Ruiz F. C., Springer, Berlin, Heidelberg, Deutschland, 2003.

Kostic, B., Becht, A., und Aigner, T.: 3-D sedimentary architecture of a Quaternary gravel delta (SW-Germany): Implicati- ons for hydrostratigraphy, Sediment Geol, 181, 147-171, https://doi.org/10.1016/j.sedgeo.2005.07.004, 2005.

Kroemer, E.: Sedimententnahme und Datierungen in der Verlandungszone des Tüttensees, online aufrufbar: https://www.lfu.bayern.de/geologie/doc/tuettensee_ datierungen_kurztext_kea_end.pdf (letzter Zugriff: 18. März 2020), 2009.

Landesamt für Vermessung und Geoinformation: Topographische Karte 1:25 000, Blatt 8141 Traunstein, München, Deutschland, 2007.

Liritzis, I., Zacharias, N., Polymeris, G. S., Kitis, G., Ernstson, K. Sudhaus, D., Neumair, A., Mayer, W., Rappenglück, M. A., and Rappenglück, B.: The Chiemgau meteorite impact and tsunami event (Southeast Germany): First OSL dating, Mediterr. Archaeol. Ar., 10, 17-33, 2010.

Martini, I. P.: Pleistocene glacial fan deltas in southern Ontario, Canada, in: Coarse-Grained Deltas, edited by: Colella, A. and Prior, B., Blackwell Scientific, Oxford, UK, IAS Spec Pub., 10, 281295, 1990.

Miall, A. D.: A review of the braided-river depositional environment, Earth-Sci. Rev., 13, 1-62, https://doi.org/10.1016/00128252(77)90055-1, 1977.

Nemec, W., Lonne, I., and Blikra, L. H.: The Kregnes moraine in Gauldalen, west-central Norway: Anatomy of a Younger Dryas proglacial delta in a palaeofjord basin, Boreas, 28, 454-476, https://doi.org/10.1111/j.1502-3885.1999.tb00234.x, 1999.

Papadeas, G.: Hydrogeologie und Hydrochemie des ChiemseeTraun-Gebietes mit quartärgeologischen Spezialuntersuchungen, Dissertation Technische Universität München, München, Deutschland, 107 S., 1972.

Penck, A.: Die Vergletscherung der deutschen Alpen, ihre Ursache, periodische Wiederkehr und ihr Einfluß auf die Bodengestaltung, Barth, Leipzig, Deutschland, 483 S., 1882.

Penck, A. und Brückner, E.: Die Alpen im Eiszeitalter, 3 Bände, Leipzig, Deutschland, 1199 S., 1909.

Peters, R. and Jaffe, B. E.: Identification of tsunami deposits in the geologic record; developing criteria using recent tsunami deposits, U.S. Geological Survey Open-File Report 2010-1239, Reston, Virginia, USA, 39 pp., 2010.

Pettijohn, F. J., Potter, P. E., and Siever, R.: Sand and Sandstone, Springer, Berlin, Deutschland, 618 S., 1973.

Poßekel, J. and Ernston, K.: Anatomy of young meteorite craters in a soft target (Chiemgau Impact strewn field, SE Germany) from Ground Penetrating Radar (GPR) measurements, 50th Lunar and Planetary Science Conference 2019, 18.-22. März 2019, The Woodlands, Texas, USA, LPI Contrib. No. 2132: 3, 2019.

Reineck, H.-E. and Singh, I. B.: Depositional Sedimentary Environments, Springer, Berlin, Heidelberg, https://doi.org/10.1007/9783-642-96291-2, 1973.

Russell, A. J.: Controls on the sedimentology of an icecontact jökulhlaup-dominated delta, Kangerlussuaq, west Greenland, Sediment Geol., 193, 131-148, https://doi.org/10.1016/j.sedgeo.2006.01.007, 2007.

Schmeidl, H.: Die Moore des Kartenblattes 8141 Traunstein, in: Geologische Karte von Bayern 1:25000, Erläuterungen zum Blatt Nr. 8140 Prien a. Chiemsee und zum Blatt Nr. 8141 Traunstein, Herausgeber: Ganss, O., Bayerisches Geologisches Landesamt, München, Deutschland, 227-239, 1977. 
Schneider, M.: Der hochwürmzeitliche Rückzug des Eisrandes im Ammersee-Lobus des Loisach-Gletschers - Zur Frage eines ehemals erhöhten Seespiegels, Geologica Bavarica, 99, 223-244, 1995.

Smith, B., Pages, A., Huber, R., Darga, R., and Klump, J.: If you wish upon a star. Chiemite: an Anthropocene Pseudo-Impactite, EGU General Assembly, 7.-12. April 2019, Wien, Austria, Geophys. Res. Abstr., 21, EGU2019-18826-1, 2019.

Tengler, R.: Jezero Tuttensee, online aufrufbar: http://www. georadar.rtg-tengler.cz/jezero-tuttensee (letzter Zugriff: 26. Mai 2019), 2015.

Troll, K.: Der diluviale Inn-Chiemsee-Gletscher. Das geographische Bild eines typischen Alpenvorlandgletschers, Forschungen zur Deutschen Landes- und Volkskunde, 23, 121 S.,1924.

Van Husen, D.: Zur Fazies und Stratigraphie der jungpleistozänen Ablagerungen im Trauntal (mit quartärgeologischer Karte), Jb. Geol. BA, 120, 1-130, 1977.
Veit, E.: Das Seetonbecken von Übersee, in: Geologische Karte von Bayern 1:25000, Erläuterungen zum Blatt Nr. 8140 Prien a. Chiemsee und zum Blatt Nr. 8141 Traunstein, Herausgeber: Ganss, O., Bayerisches Geologisches Landesamt, München, Deutschland, 212-214, 1977.

Völkel, J., Murray, A., Leopold, M., and Hürkamp, K.: Colluvial filling of a glacial bypass channel near the Chiemsee (Stöttham) and its function as geoarchive, Z. Geomorphol., 56, 371-386, 2012.

Wilhelm, F.: Die Neuauslotung des Chiemseebeckens, Münchner Geographische Hefte, 15, 50 S., 1958.

Wünnemann, K., Reimold, U., und Kenkmann, T.: Postuliertes Impaktereignis im Chiemgau nicht haltbar, Geowissenschaftliche Mitteilungen (GMIT), 27, 19-21, 2007. 